\title{
Effect of Temperature Variation on Modal Frequency of Reinforced Concrete Slab and Beam in Cold Regions
}

\author{
Hanbing Liu, Xianqiang Wang, and Yubo Jiao \\ College of Transportation, Jilin University, Changchun 130025, China \\ Correspondence should be addressed to Yubo Jiao; jiaoyb@jlu.edu.cn
}

Received 3 January 2016; Revised 17 May 2016; Accepted 1 June 2016

Academic Editor: Mickaël Lallart

Copyright (C) 2016 Hanbing Liu et al. This is an open access article distributed under the Creative Commons Attribution License, which permits unrestricted use, distribution, and reproduction in any medium, provided the original work is properly cited.

\begin{abstract}
Changes of modal frequencies induced by temperature variation can be more obvious than those caused by structural damage, which will lead to the false damage identification results. Therefore, quantifying the temperature effect on modal frequencies is a critical step to eliminate its interference in damage detection. Due to the nonuniform and time-dependent characteristics of temperature distribution, it is insufficient to obtain the reliable relationships between temperatures and modal frequencies using temperatures in air or at surface. In this paper, correlations between measured temperatures (air temperature, surface temperature, mean temperature, etc.) and modal frequencies for the slab and beam are comparatively analyzed. And the quantitative models are constructed considering nonuniform temperature distribution. Firstly, the reinforced concrete slab and beam were constructed and placed outside the laboratory to be monitored. Secondly, the correlation coefficients between modal frequencies and three kinds of temperatures are calculated, respectively. Thirdly, simple linear regression models between mean temperature and modal frequencies are established for the slab and beam. Finally, five temperature variables are selected to construct the multiple linear regression models. Prediction results reveal that the proposed multiple linear regression models possess favorable accuracy to quantify the temperature effect on modal frequencies considering nonuniform temperature distribution.
\end{abstract}

\section{Introduction}

In order to guarantee the safety operation of structures, structural health monitoring (SHM) systems have been widely implemented on the existing and newly built bridges in the past few decades [1-3]. Vibration-based Damage Identification (VBDI), as one of extremely important parts of SHM system, has been developed to monitor bridge performance and identify structural damage [4-6]. However, a practical difficulty exists because modal parameters vary with the changing environmental conditions. In order to avoid the false damage identification results, the changes of modal parameters caused by environmental variation must be understood, quantified, and discriminated from those caused by structural damage [7-10].

Numerous investigations have indicated that temperature is the most important environmental factor affecting structural vibration properties $[11,12]$. And its effect can be more significant than that caused by structural damage [13].
Corresponding researches have also demonstrated that mode shapes are not sensitive to temperature variation, and the change of modal damping may be masked by measurement noise [14-16]. Therefore, the temperature effect on modal frequencies has attracted much more attention. Researchers from Los Alamos National Laboratory monitored the Alamosa Canyon Bridge in New Mexico during 24 hours. They found that the first three modal frequencies varied about $4.7 \%, 6.6 \%$, and $5.0 \%$, when the temperature of bridge deck changed by about $22^{\circ} \mathrm{C}[17,18]$. It was more significant than the changes of modal frequencies caused by artificial cut in I-40 Bridge [19]. Peeters and De Roeck [20] reported that the first four modal frequencies of Z24 Bridge in Switzerland varied by $14 \%-18 \%$ during monitoring period of 10 months. There was a bilinear relationship between measured frequencies and temperatures above and below $0^{\circ} \mathrm{C}$ because of the asphalt layer freezing at cold temperature. Later progressive damage tests indicated that modal frequencies decreased by less than $10 \%$ till final destructive damage [21]. 
As indicated by these researches, structural damage cannot be accurately identified if temperature effect is not quantified and eliminated.

During the past 20 years, considerable efforts have been devoted to investigating temperature effect on modal frequencies of RC bridges. Askegaard and Mossing [22] continuously monitored a three-span RC bridge for three years, and seasonal change of modal frequencies reached $10 \%$. Desjardins et al. [23] studied the modal frequencies and average girder temperature of Confederation Bridge during monitoring period of 6 months. The variation of temperature from $-20^{\circ} \mathrm{C}$ to $25^{\circ} \mathrm{C}$ led to the reduction in modal frequencies by $4 \%$. Liu and DeWolf [24] found that the modal frequencies changed about $6 \%$ during one full year. And a linear regression analysis demonstrated that the modal frequencies were decreased by $0.8 \%, 0.7 \%$, and $0.3 \%$ as temperature increases by one degree Celsius. Mosavi et al. [25] monitored the vibration responses and temperature of a two-span steelconcrete composite bridge during $24 \mathrm{~h}$ period. Frequencies in all modes changed 1-2\% from night to noon and did not change significantly from night to morning. In summary, it has been widely observed that temperature significantly affects the modal frequencies of $\mathrm{RC}$ bridges with a negative correlation $[26,27]$.

Some researchers have been investigating the correlation and evaluating the degree of temperature influence on modal frequencies based on field test data [28]. However, vibration test in practical engineering is easily affected by external factors (service load, wind, temperature, boundary condition, damage, measurement noise, etc.) [29]. It is difficult to separate the effect of temperature on modal frequencies from others, which results in the unconvinced correlations between measured modal frequencies and temperature. Therefore, the controlled laboratory experiments are necessary and imperative to provide accurate and reliable results regarding the temperature effect on modal frequencies. Xia et al. [15] conducted an experiment on a two-span continuous concrete slab out of laboratory for nearly two years. It was found that the negative correlation between modal frequencies and air temperature could be observed for the first four modes. Comparative study with cantilever beams made of steel and aluminum indicated that the modal frequencies variations of RC slab were much larger than those of metallic beams [13]. For these laboratory experiments and field testes, air temperature and surface temperature are measured to discover the correlations with modal frequencies. However, the temperature distribution in RC bridge is nonuniform and time-dependent. The relationships between modal frequencies and temperature at surface (or in air) are incomplete and unreliable.

Considering that the relationships between modal frequencies and temperature cannot be sufficiently captured using air temperature or surface temperature, Xia et al. [30] investigated the variation of modal frequencies versus nonuniform temperature distribution for a RC slab. It was clearly shown that modal frequencies decreased with the increasing of temperature. In addition, a better linear correlation between modal frequencies and structural temperatures was observed than air temperature and surface temperature. However, the tests are only carried out from 8:00 am to
10:00 pm on 11 February 2009. During test period, air temperatures only fluctuated from $17^{\circ} \mathrm{C}$ to $27^{\circ} \mathrm{C}$. It is insufficient to investigate the correlation and quantify temperature influence on modal frequencies, especially in cold regions. Moreover, temperature along width direction is assumed to be uniformly distributed, and nonuniform temperature distribution is only considered along vertical direction in Xia et al's research. In practice, the temperature distribution of an entire bridge is generally nonuniform throughout the cross section. Therefore, studying the correlation and quantifying temperature effect using nonuniform temperature distributions along both width and height directions are necessary for engineering application of damage identification methods.

This paper aims to investigate the correlations between modal frequencies and temperatures for RC slab and beam in cold regions and quantify the temperature effect. The RC slab and beam were constructed and placed outside the laboratory to periodically measure the modal frequencies and temperatures (air temperature, surface temperature, mean temperature, etc.). Correlations between modal frequencies and three kinds of temperatures are contrastively analyzed. In addition, simple linear regression models (SLRM) between modal frequencies and mean temperature are established. And the temperature effect on modal frequencies is evaluated based on thermal mechanics theory and thermal properties of concrete. In order to improve the accuracy of quantification, multiple linear regression models (MLRM) are developed to formulate the relationship between modal frequencies and nonuniform temperature distribution. A better prediction performance indicates that MLRM can be used to accurately quantify temperature effect on modal frequencies for structural health monitoring and damage identification.

\section{Description of Experiment}

2.1. RC Slab and Beam. The RC slab and beam constructed for monitoring temperatures and modal frequencies are shown in Figure 1. The slab is $600 \mathrm{~mm}$ wide and $150 \mathrm{~mm}$ high, and beam is $300 \mathrm{~mm}$ wide and $400 \mathrm{~mm}$ high. The lengths of them are both $4000 \mathrm{~mm}$, and calculated span lengths are $3700 \mathrm{~mm}$. RC slab and beam are simply supported on concrete piers by plate rubber supports. A $150 \mathrm{~mm}$ overhang is present at each end of the slab and beam. In order to avoid the localized damage at support positions, the metal plates with $5 \mathrm{~mm}$ thickness are embedded into slab and beam over supports. In addition, the concrete blocks with the length of $400 \mathrm{~mm}$ and the same cross section dimensions as the RC slab and beam are constructed and placed on the side of slab and beam. They are used to measure the mass variations, which can reflect the effect of air humidity on the mass of RC slab and beam. The RC slab, beam, and corresponding concrete blocks were produced on 8 June 2015. Design strength of concrete is $40 \mathrm{MPa}$, and the mixture proportions are listed in Table 1. Common Portland cement of grade 42.5 (normal type) containing $20 \%$ active admixture is used as cementitious material. Natural river sand (medium sand) with fineness modulus 2.7 is adopted as fine aggregate. And crushed gravels with a nominal maximum size of $31.5 \mathrm{~mm}$ are used as 


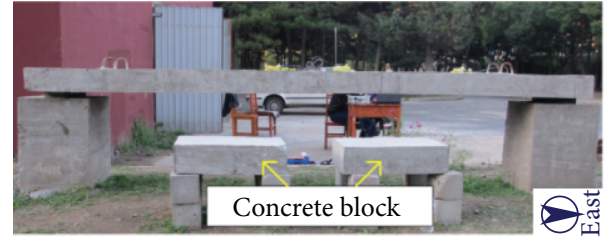

(a) Slab

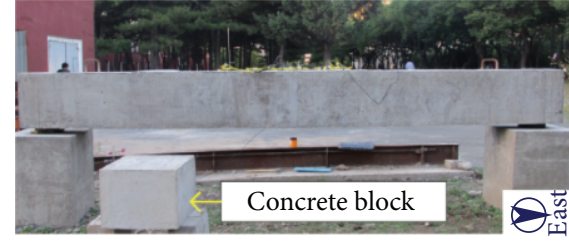

(b) Beam

FIgURE 1: RC slab and beam constructed for monitoring.

TABLE 1: Mixture proportions of designed concrete.

\begin{tabular}{lcc}
\hline Materials & Unit & Nominal proportions \\
\hline Cement & $\mathrm{kg} / \mathrm{m}^{3}$ & 378 \\
Coarse aggregate & $\mathrm{kg} / \mathrm{m}^{3}$ & 1230 \\
Fine aggregate & $\mathrm{kg} / \mathrm{m}^{3}$ & 607 \\
Water & $\mathrm{kg} / \mathrm{m}^{3}$ & 185 \\
Water/cement ratio & & 0.49 \\
\hline
\end{tabular}

coarse aggregate. Three concrete cube specimens $(150 \mathrm{~mm} \times$ $150 \mathrm{~mm} \times 150 \mathrm{~mm}$ ) were poured at the same time with slab and beam. The compressive strengths of cube specimens are measured by crushing the specimens cured for 28 days under the standard curing condition of $20 \pm 3^{\circ} \mathrm{C}$ and $95 \%$ relative humidity [31]. Mean value of tested compressive strengths is $48.5 \mathrm{MPa}$, which is larger than the designed one. The high quality of materials, favorable curing condition, and large extra coefficient of cement could account for the larger tested compressive strength of cube specimens. In order to reduce the influence of inadequate curing on experimental tests, RC slab and beam were covered in plastics after pouring concrete and cured on the ground outside the laboratory for more than 90 days. They were hoisted and placed at supports on 12 September 2015 for installing the measurement equipment and preparing to start the tests.

2.2. Test Equipment. The temperature and humidity monitoring systems are designed to measure the internal temperatures of slab and beam, air temperature, and air humidity. All temperature sensors adopted to measure the internal temperatures of slab and beam are type $\mathrm{T}$ thermocouples produced by Omega Engineering. Type $\mathrm{T}$ thermocouples are made by copper and constantan, and measurement range of them is from -250 to $260^{\circ} \mathrm{C}$. A TP-2307 digital temperature and humidity sensor manufactured by TOPRIE Electronics Corporation in China is chosen to measure the air temperature and humidity. It features $0.3^{\circ} \mathrm{C}$ temperature resolution and $0.3 \%$ humidity resolution and can measure the air temperature ranging from -40 to $125^{\circ} \mathrm{C}$ and relative humidity ranging from $0 \%$ to $99 \%$. A TP700 multichannel data recorder including thermocouple and humidity input module is employed to sample the data collected by type $\mathrm{T}$ thermocouples and TP-2307 sensor. It features an autozero channel, a coldjunction compensator, and automatic voltage-temperature conversions for common thermocouple types. Due to the operating temperature ranging from 0 to $50^{\circ} \mathrm{C}$, it is installed in laboratory to ensure the accuracy of measurement. Type $\mathrm{T}$ thermocouples are connected to TP700 data recorder using shielded thermocouple compensation lead. Connection between two compensation leads is achieved by malefemale plugs, and the metal wire is covered with heat-shrink tubing [32]. Thermocouple compensation lead is connected into the laboratory using a sealed PVC conduit.

In order to monitor the temperatures in prefabricated $\mathrm{RC}$ slab and beam, type $\mathrm{T}$ thermocouples are embedded in cross sections at mid-spans of the slab and beam. There are two reasons accounting for the layout of type $\mathrm{T}$ thermocouples. Firstly, thermal transmission mainly occurs along width and height directions with respect to the length because the size of length is significantly larger than width and height. Secondly, the slab and beam receive the uniform sunlight along the length direction as they are set along East-West directions. Therefore, the temperature along length direction is assumed to be uniformly distributed, and the measurements of temperatures in the cross sections of slab and beam are the main concerns. Specific layouts of thermocouples in cross sections at mid-spans of the slab and beam are shown in Figure 2. "SH" represents thermocouples along height direction in slab, while "SW" represents the thermocouples along width direction. Similarly, "BH" and "BW" represent the thermocouples along height and width directions in beam, respectively. In order to fix the thermocouples in accurate position, preformed concrete strips containing type $\mathrm{T}$ thermocouples are located at predetermined position before pouring concrete, as illustrated in Figure 3. In addition, the TP-2307 sensor is fixed on the undersurface of the slab using adhesive mounting squares and zip ties to monitor the air temperature and humidity.

DH131E accelerometers manufactured by Donghua Testing Technology Corporation in China are selected as the vibration sensors. The accelerometer features a sensitivity of $1 \mathrm{mV} / \mathrm{g}$, a frequency range of $1-8000 \mathrm{~Hz}$, small size $(\phi 10 \times$ $16 \mathrm{~mm})$, and light weight $(5.5 \mathrm{~g})$. The operating temperature ranging from -40 to $80^{\circ} \mathrm{C}$ makes it ideal for outdoor application. The magnetic bases are fixed on the upper surface of slab and beam using metal/concrete epoxy, and accelerometers are mounted on the magnetic bases. A DH5922 type dynamic signal measurement and analysis system is used to measure and analyze acceleration response. It includes sixteen 24-bit Integrated Electronics Piezoelectric (IEPE) input channels and supports sampling rates of up to $51.2 \mathrm{kHz}$. Antialiasing filters and timebase export for tight synchronization between 


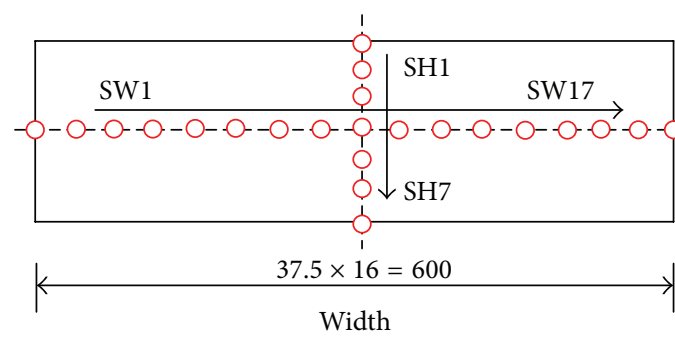

(a) Slab

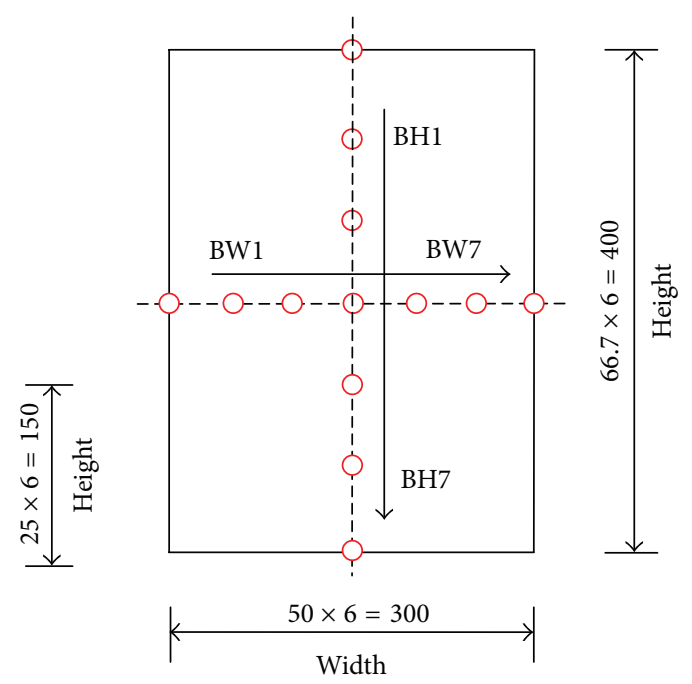

(b) Beam

FIgURE 2: Layout of thermocouples in cross sections at mid-spans of slab and beam (unit: $\mathrm{mm}$ ).

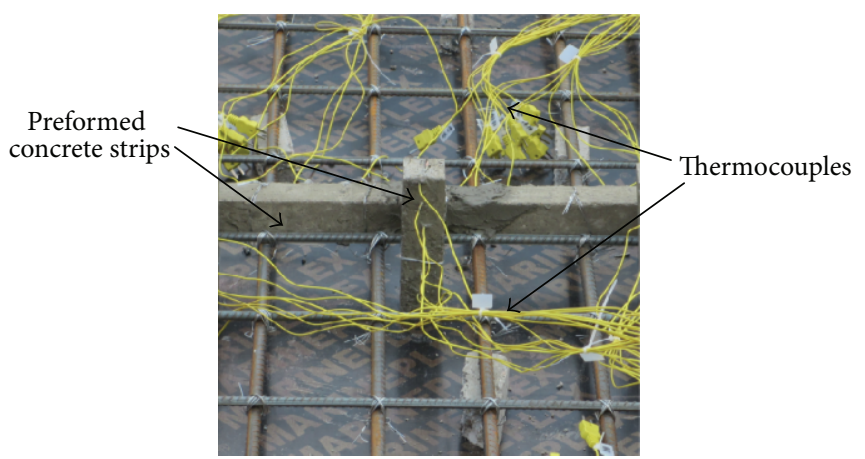

FIgURE 3: Positioning of type T thermocouples in cross section at mid-span.

channels are equipped. The DH5922 system has an operating temperature range of 0 to $40^{\circ} \mathrm{C}$, and it is placed in laboratory. The accelerometers are connected with data acquisition device using L5 coaxial extension cables with lengths of $15 \mathrm{~m}$. Extension cables are run into the laboratory in a sealed PVC conduit along with thermocouple compensation leads.

Two DH131E accelerometers are installed at mid-span and at $3 / 10$ of the span length from one end to monitor vertical vibration. The slab and beam are excited using a rubber hammer at 7/10 of span length along vertical direction. The first four vertical mode shapes calculated by numerical model are illustrated in Figure 4, and corresponding layouts of accelerometers and excitation point are also demonstrated. It is assumed that there are no motions at the supports. As can be seen from Figure 4, the locations of $1^{\#}$ accelerometer and excitation point avoid the nodes of mode shapes. $2^{\#}$ accelerometer is used to identify the modal frequencies of modes 1 and 3 , and $1^{\#}$ accelerometer is used to identify the first four modal frequencies. Although node 7 is not the optimal choice of excitation location for the first four

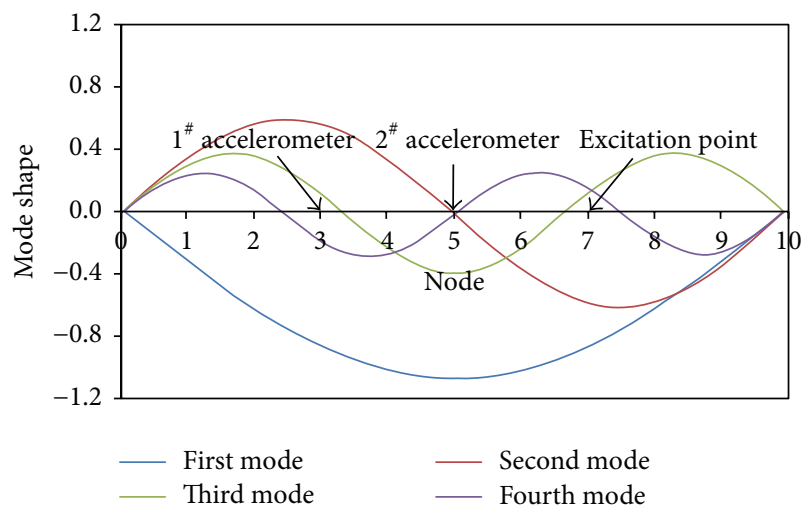

FIgURE 4: Locations of accelerometers and excitation point.

vertical modes, it is successful in exciting and identifying the first seven modal frequencies, which is helpful for future investigation. 
2.3. Test Procedures. The tests are carried out from 20 September 2015, and the slab and beam are exposed to external environment from then. Modal testing is performed to measure the vibration responses of the slab and beam at twohour intervals from 8:00 am to 10:00 pm in every day of monitoring. At the same time, temperatures and air humidity are recorded by TP700 data recorder at a rate of one sample per minute. No measurements are taken from 10:00 pm to 8:00 am in the next day because the sunlight disappears and air temperature slightly changes during this period. The modal frequencies insignificantly change, and there is no obvious difference between the measurement results at 10:00 pm and those measured during the period from 10:00 pm to 8:00 am. Mosavi et al. [25] also found that the first five modal frequencies did not have a noticeable change between night and morning measurements, while an almost $2 \%$ change in modal frequencies can be observed in all modes for the noon measurement. In addition, the monitoring was discontinuously performed for the RC slab and beam due to the restrictions of measurement equipment. Therefore, the measurements from 10:00 pm to 8:00 am are not taken in this investigation.

As for the modal testing, DH5922 system samples a 16second data from the four acceleration channels at a $5120 \mathrm{~Hz}$ sampling rate. Data processing is performed by DHDAS-2013 software platform, which is an important part of DH5922 system. Firstly, the recorded sample data is bandpass-filtered between 10 and $1000 \mathrm{~Hz}$ using a finite impulse response filter. Secondly, the Hamming window with $50 \%$ overlap is used to intercept acceleration signal. The number of spectrum lines is set as 6400 , and the obtained frequency resolution is $0.156 \mathrm{~Hz}$. Finally, modal frequencies are calculated and extracted by frequency spectrum analysis using fast Fourier transform (FFT). For example, two samples of data collected from accelerometers installed on the slab on 13 October 2015 at 8:00 am are shown in Figure 5. Both the time history of acceleration signal and corresponding amplitude spectrum are illustrated.

\section{Analysis of Test Results}

Due to the restrictions of measurement equipment, RC slab and beam are discontinuously monitored. Measurements are completed for each of 112 samples from fourteen days during the period beginning on 20 September 2015 and ending on 9 December 2015. A total of 112 samples are sorted in measurement time order. The samples measured on 1 November 2015 are chosen as testing samples to verify the prediction performances of quantitative models, and other 104 samples are used to analyze the correlation and construct the quantitative models.

3.1. Temperature Distribution. Under the influence of solar radiation, air temperature, and thermal inertia of concrete, temperature distributions in RC slab and beam are usually nonuniform and time-dependent. Measured temperatures from selected thermocouples in cross section at mid-span during the monitoring period are shown in Figure 6. It is noted that temperatures at the surface of beam are monitored by thermocouples (BH1, BH7, BW1, and BW7), and
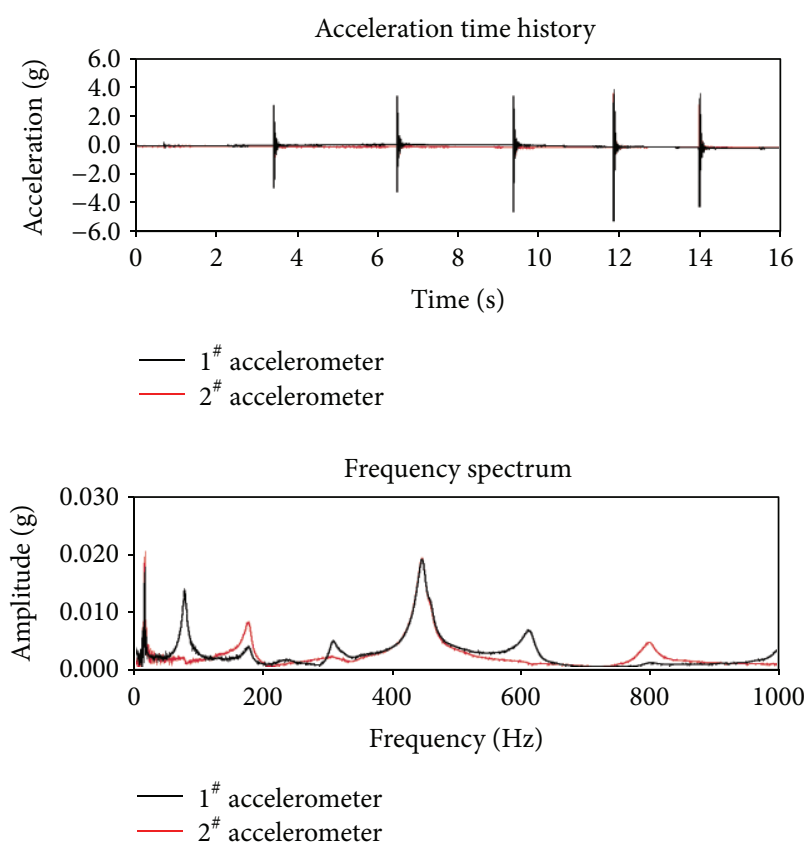

FIGURE 5: Acceleration time history and corresponding amplitude spectrum.

temperature at the center of cross section is measured by thermocouple BH4. Similar to the beam, thermocouples (SH1, SH7, SW1, SW17, and SH4) are used to measure the temperatures at the corresponding positions of slab. It is obvious to observe that thermocouples at SW1 and BW1 on the south side of slab and beam receive direct sunlight, and their temperatures are higher than others. The significant differences of temperatures at the same time demonstrate the nonuniform temperature distributions in the slab and beam.

In order to specifically exhibit the nonuniform temperature distributions in slab and beam, temperatures measured on 16 October 2015 at 2:00 pm are shown in Figure 7. It can be found that the temperature distributions are nonuniform not only along height direction but also along width direction in cross section at mid-span. Compared with slab, nonuniform temperature distributions in beam are more obvious. This can be accounted for by the fact that the sizes of height and width of beam are much closer and thermal transmissions occur at two dimensions with similar levels.

3.2. Variation of Modal Frequency. The identified first four modal frequencies and corresponding air temperatures are shown in Figures 8 and 9. Modal frequencies change significantly with the variation of temperatures. And the higher values of modal frequencies generally occur at the lower temperatures. It is indicated that the modal frequencies increase with temperature decreasing. Clear correlations between modal frequencies and air temperatures can be observed.

Statistics of the identified modal frequencies during monitoring period are summarized in Table 2. Variation range of modal frequency is the difference between maximum and minimum values of identified modal frequencies for a 


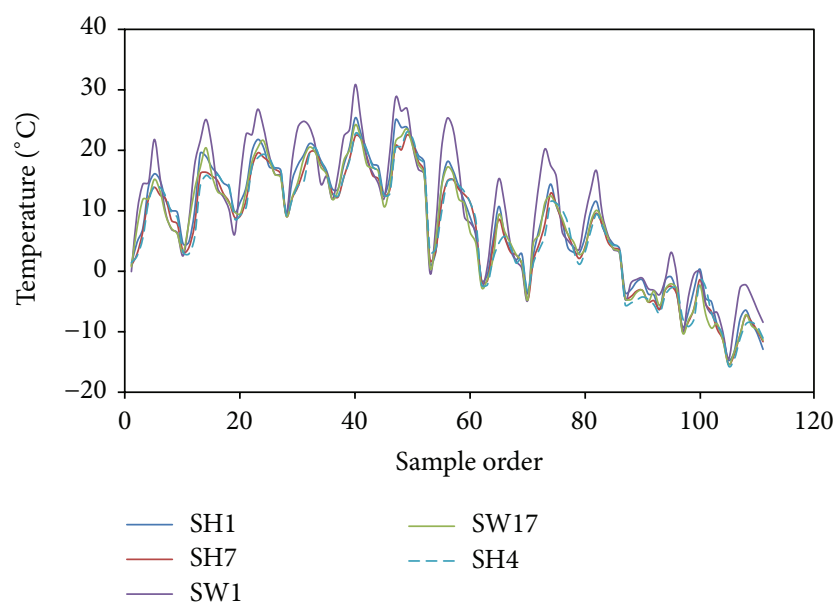

(a) Slab

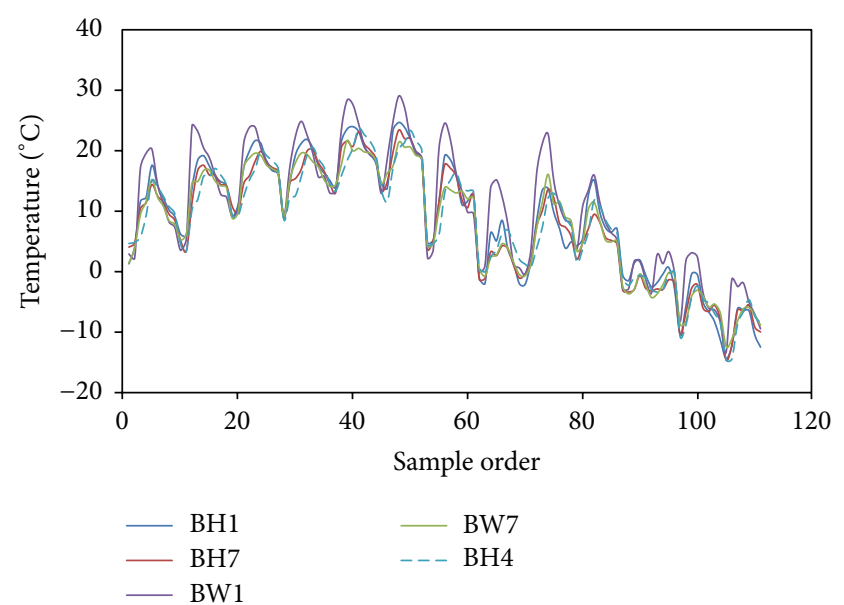

(b) Beam

FIGURE 6: Temperature variations of slab and beam during monitoring period.

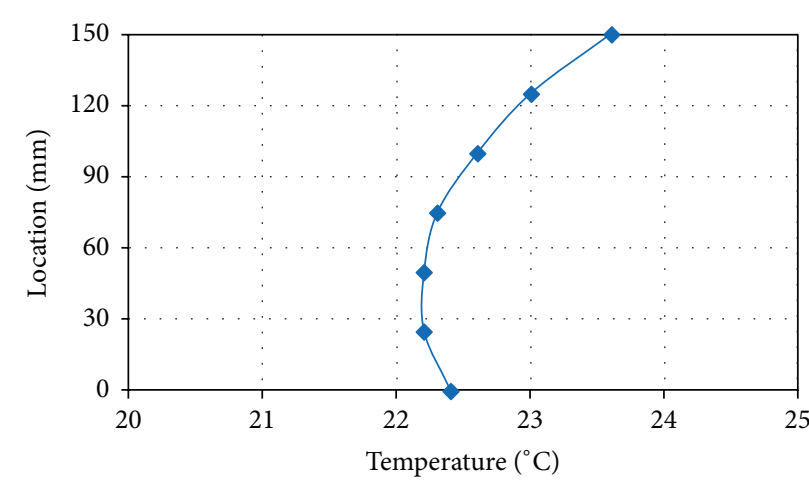

(a) Along height direction of slab

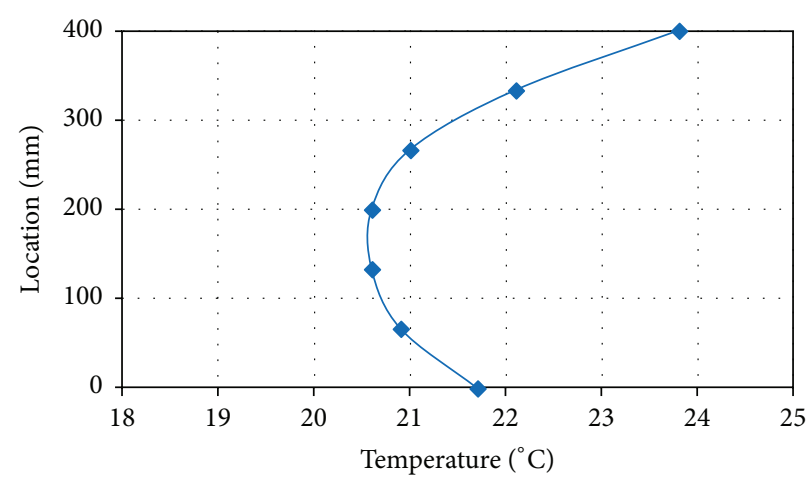

(c) Along height direction of beam

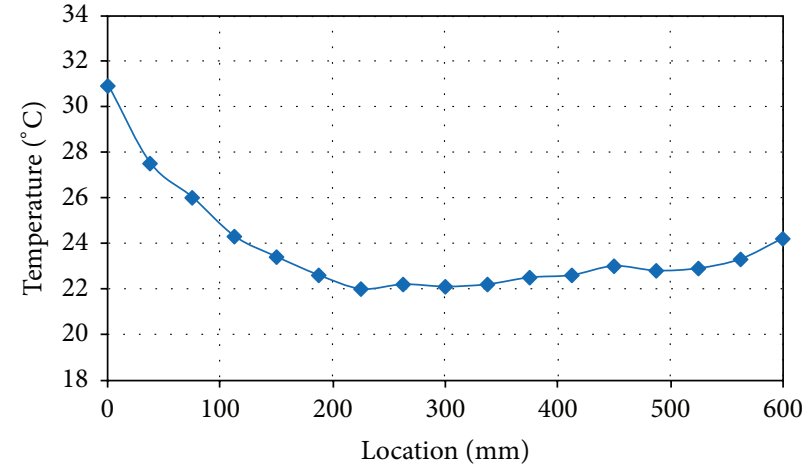

(b) Along width direction of slab

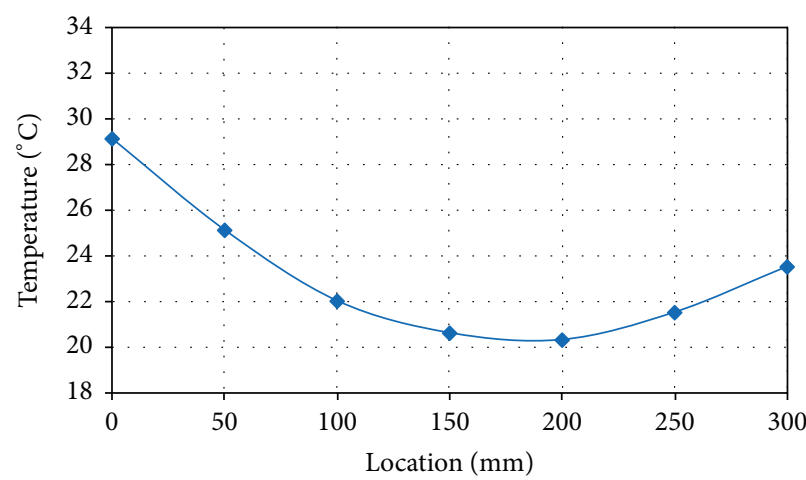

(d) Along width direction of beam

FIgURE 7: Temperature distribution on 16 October 2015 at 2:00 pm.

specific mode. Mean value of modal frequency is calculated by averaging the identified modal frequencies for a specific mode. The relative variation is defined as [33]

$$
\xi=\frac{f_{\max }-f_{\min }}{\bar{f}} \times 100 \%,
$$

where $f_{\max }, f_{\min }$, and $\bar{f}$ are the maximum, minimum, and mean values of identified modal frequencies for a specific mode, respectively. During the monitoring period, the variation ranges of first four modal frequencies are 1.518, 7.310, 14.969 , and $19.634 \mathrm{~Hz}$ for the slab and 3.9053, 18.250, 46.252, and $37.565 \mathrm{~Hz}$ for the beam. Modal frequencies of the first 


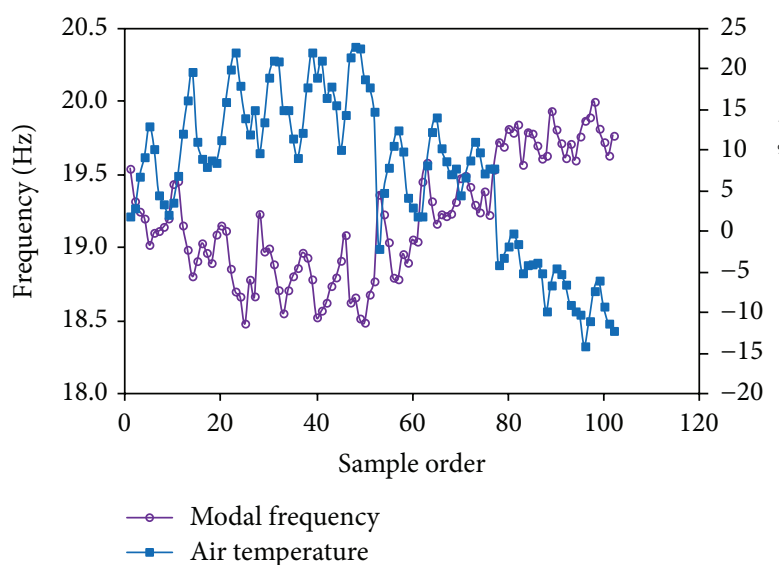

(a) First mode

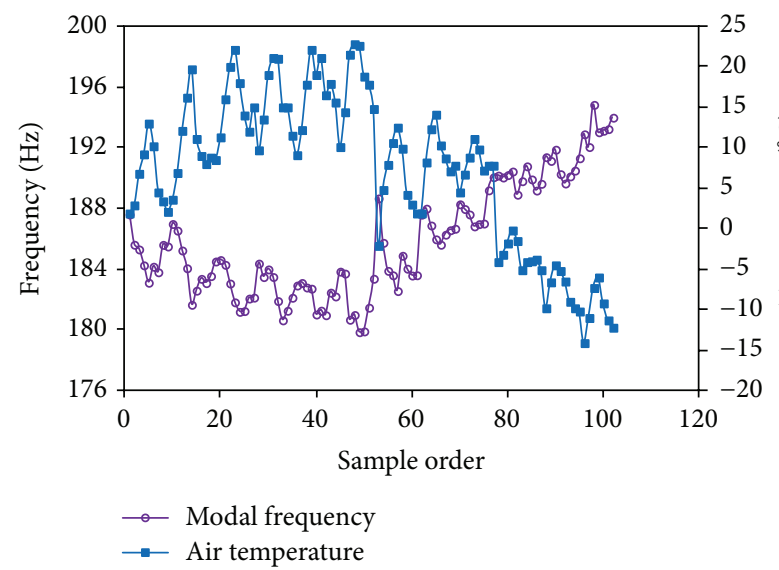

(c) Third mode

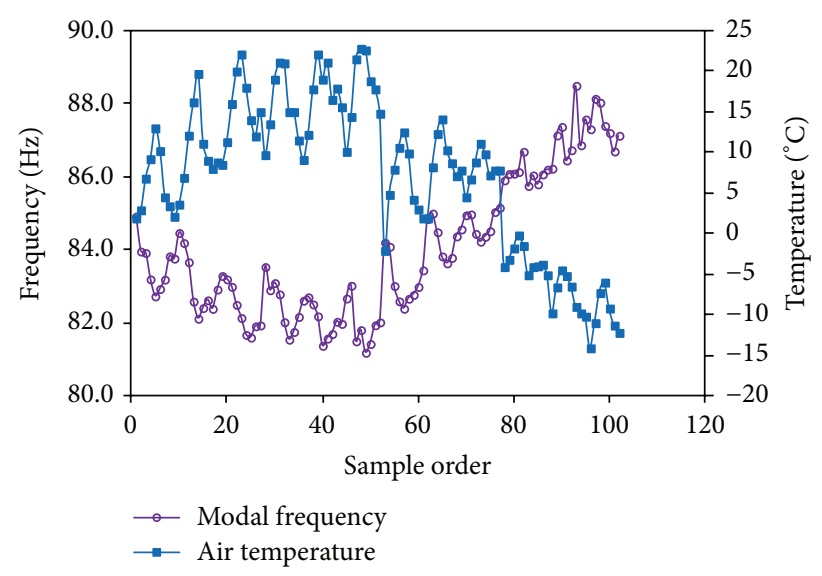

(b) Second mode

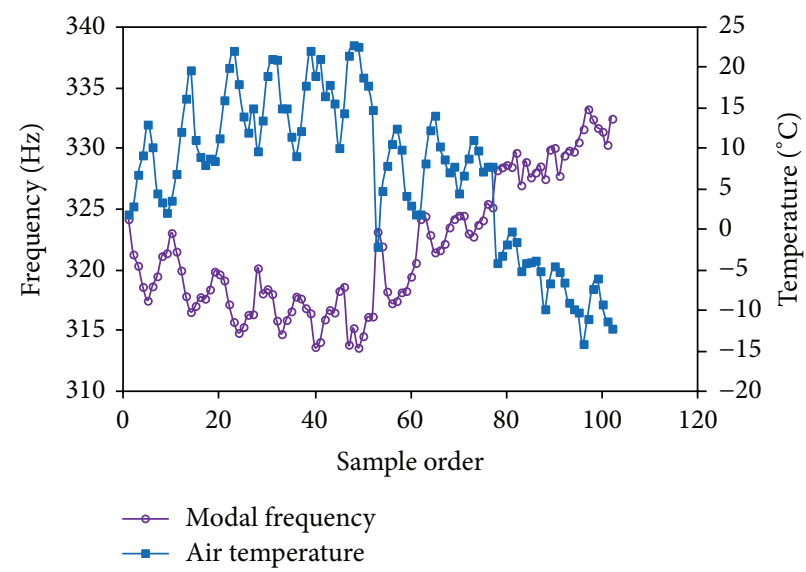

(d) Fourth mode

FIGURE 8: Identified modal frequencies of slab versus air temperature.

TABLE 2: Statistics of identified modal frequencies.

\begin{tabular}{lcccc}
\hline Structure & Mode & $\begin{array}{c}\text { Variation } \\
\text { range }(\mathrm{Hz})\end{array}$ & $\begin{array}{c}\text { Mean value } \\
(\mathrm{Hz})\end{array}$ & $\xi(\%)$ \\
\hline \multirow{3}{*}{ Slab } & 1 & 1.518 & 19.198 & 7.907 \\
& 2 & 7.310 & 83.971 & 8.705 \\
& 3 & 14.969 & 185.870 & 8.053 \\
& 4 & 19.634 & 321.689 & 6.103 \\
\hline \multirow{3}{*}{ Beam } & 1 & 3.9053 & 51.807 & 7.538 \\
& 2 & 18.250 & 145.299 & 12.56 \\
& 3 & 46.252 & 504.599 & 9.167 \\
& 4 & 37.565 & 742.047 & 5.062 \\
\hline
\end{tabular}

four modes vary by $5 \%-12 \%$, while air temperatures change from $-14.1^{\circ} \mathrm{C}$ to $22.8^{\circ} \mathrm{C}$, which is sufficient to mask those caused by structural damage. Because of the inherent variability in modal frequency caused by temperature, the correlation and quantitative models must be developed for eliminating temperature effect on structural damage detection.
3.3. Mass Variation. Concrete blocks have the same crosssectional dimensions with the RC slab and beam. They are placed on the side of slab and beam and fully exposed to external environment. Static weighing is carried out at the synchronization with modal testing. Mass variations of concrete blocks are reported in Table 3 . It is noted that the concrete blocks corresponding to the slab and beam are labeled as "A" and "B," respectively. As can be seen from Table 3, the relative variations in weights of concrete blocks are about $0.3 \%$, which indicates that the changes in the weights of RC slab and beam are generally small. Therefore, air humidity will have little contribution on the total variability of identified modal frequencies, which is consistent with the study conducted by $\mathrm{He}$ [34]. In his investigation, it is found that change in air humidity has much smaller influence on modal frequencies than change in temperature.

\section{Effect of Temperature on Modal Frequency}

4.1. Theoretical Analysis. Temperature variation affects the modal frequencies of slab and beam in a complicated way. Theoretical analysis for the temperature effect on modal 


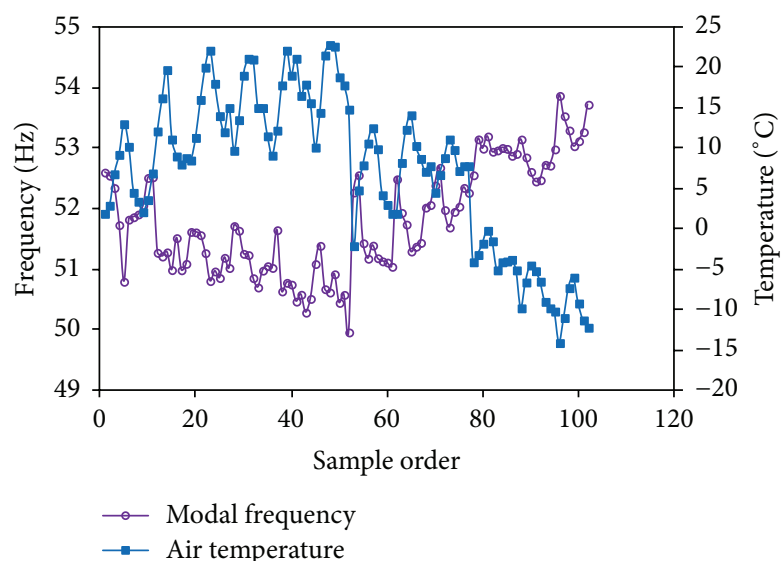

(a) First mode

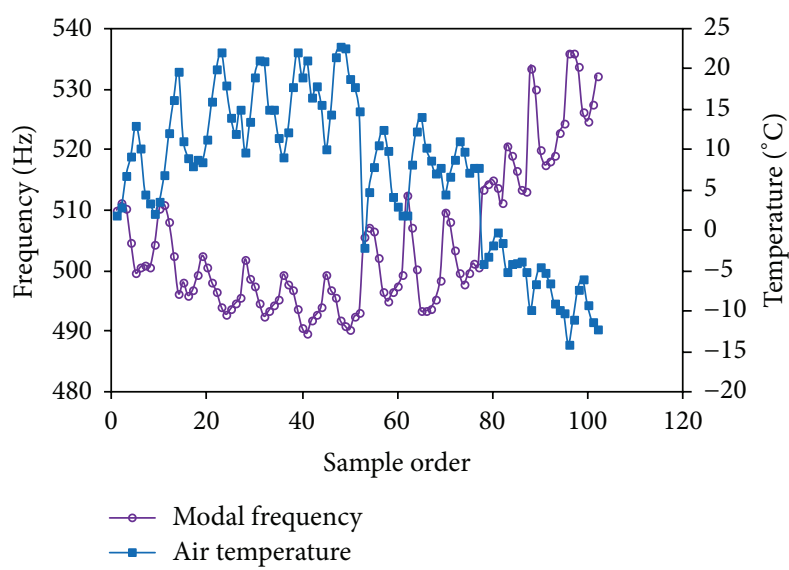

(c) Third mode

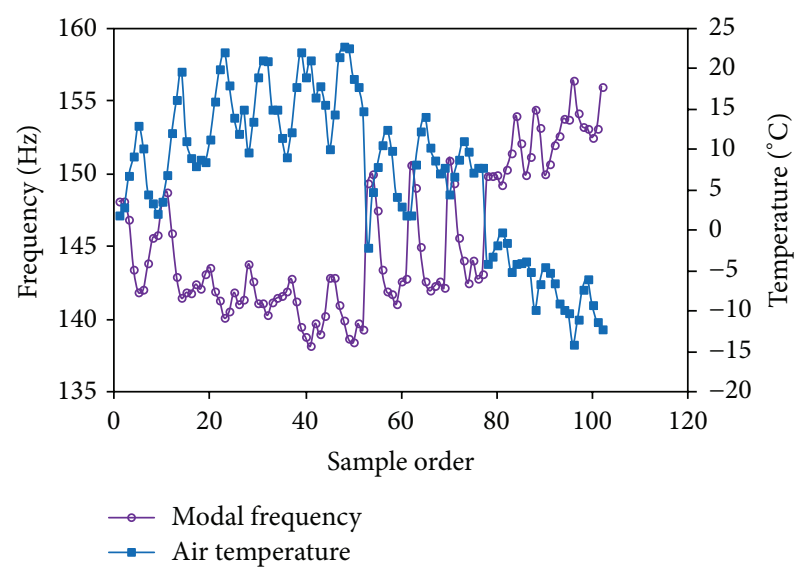

(b) Second mode

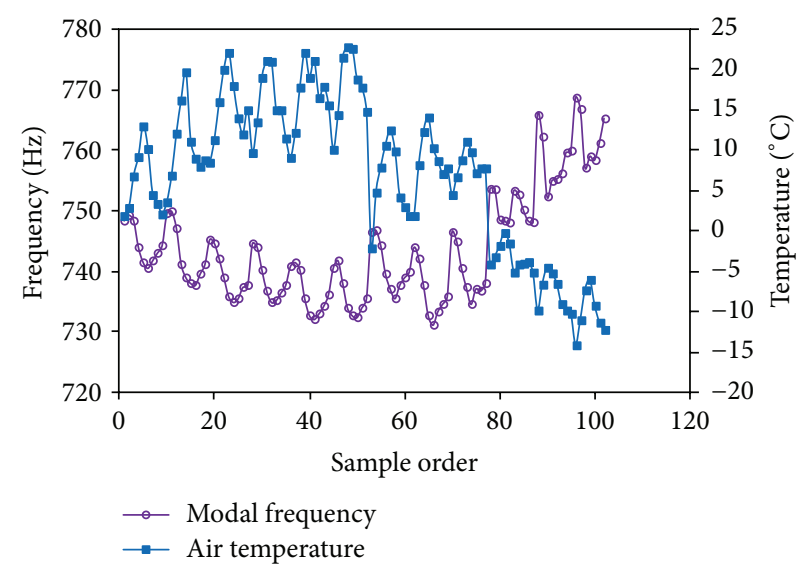

(d) Fourth mode

FIgURE 9: Identified modal frequencies of beam versus air temperature.

TABLE 3: Statistics of measured weights of concrete blocks.

\begin{tabular}{lccc}
\hline Concrete blocks & Variation range $(\mathrm{kg})$ & Mean value $(\mathrm{kg})$ & $\xi(\%)$ \\
\hline A (slab) & 0.3 & 91.15 & 0.33 \\
B (beam) & 0.4 & 117.3 & 0.34 \\
\hline
\end{tabular}

frequencies is necessary to explain the physical meaning of modal frequency changes. According to existing literatures, it is widely accepted that the concrete elasticity modulus, geometrical features, constraint, and boundary conditions of bridges are changed with temperature, which cause the variations of modal frequencies. In this paper, the elasticity modulus of concrete is being referred to as the static elasticity modulus. Xia et al. [15] assume that the mass and boundary condition of slab remain unchanged, and temperature only affects geometrical features and elasticity modulus of concrete. On this basis, theoretical derivation is established for a simply supported slab made of an isotropic material. In order to ensure the correctness and reasonability of assumptions for the research in this paper, the sliding plate rubber supports are placed at one end of slab and beam, which allow the slab and beam to move freely. As demonstrated in Table 3, relative variations in weights of concrete blocks are as small as $0.3 \%$ during the monitoring period. Therefore, it is assumed that the variations of modal frequencies would not be affected by mass and boundary condition of slab and beam but only the geometrical features and mechanical properties of material.

For a simply supported beam made of an isotropic material, its undamped vertical vibration frequency of order $n$ is expressed as

$$
f_{n}=\frac{n^{2} \pi}{2} \sqrt{\frac{E b h^{3}}{12 M l^{3}}}
$$

where $f_{n}$ is the $n$th order modal frequency; $l, b$, and $h$ are the length, width, and height of beam, respectively. $E$ is the elasticity modulus, and $M$ is the mass of beam. Variables $l, b$, $h$, and $E$ are the functions of temperature, and the variation percentage of modal frequency can be calculated by

$$
\frac{\delta f_{n}}{f_{n}}=\frac{1}{2} \frac{\delta E}{E}+\frac{1}{2} \frac{\delta b}{b}+\frac{3}{2} \frac{\delta h}{h}-\frac{3}{2} \frac{\delta l}{l},
$$

where $\delta$ represents an increment in corresponding variables. When temperature changes by $\delta T$, elasticity modulus of 
material changes by $\delta E$, and geometric length changes by $\delta L$. The thermal coefficients of linear expansion $\left(\theta_{T}\right)$ and elasticity modulus $\left(\theta_{E}\right)$ are defined as

$$
\begin{aligned}
& \theta_{T}=\frac{\delta L}{L \times \delta T}, \\
& \theta_{E}=\frac{\delta E}{E \times \delta T} .
\end{aligned}
$$

Therefore, we can obtain

$$
\begin{aligned}
\frac{\delta E}{E} & =\theta_{E} \delta T, \\
\frac{\delta b}{b} & =\theta_{T} \delta T, \\
\frac{\delta h}{h} & =\theta_{T} \delta T, \\
\frac{\delta l}{l} & =\theta_{T} \delta T .
\end{aligned}
$$

Consequently, (3) yields

$$
\frac{\delta f_{n}}{f_{n}}=\frac{1}{2}\left(\theta_{T}+\theta_{E}\right) \delta T
$$

Dimensionless rate of modal frequency change caused by temperature variation is estimated by (6). It can be used to account for the mechanism of temperature effect on modal frequencies of RC slab and beam. As for concrete, the thermal coefficient of linear expansion $\left(\theta_{T}\right)$ is about $1.0 \times 10^{-5} /{ }^{\circ} \mathrm{C}$, and the thermal coefficient of elasticity modulus $\left(\theta_{E}\right)$ is generally $-4.5 \times 10^{-3} /{ }^{\circ} \mathrm{C}[35]$. $\theta_{E}$ is significantly much larger than $\theta_{T}$, which indicates that the variations in modal frequencies subjected to temperature change are controlled by $\theta_{E}$. However, there is very limited research for $\theta_{E}$ of concrete in ambient temperature range, especially in cold regions. Extensive efforts have been contributed to study the thermal behavior of concrete at high temperature typically generated by fire.

Jiao et al. [36] investigated the changes of elasticity modulus of $\mathrm{C} 30$ concrete at temperature range from $-20^{\circ} \mathrm{C}$ to $60^{\circ} \mathrm{C}$. In their study, fifteen prism specimens $(150 \mathrm{~mm} \times$ $150 \mathrm{~mm} \times 300 \mathrm{~mm}$ ) are produced for testing the elasticity modulus under different temperatures. The mixture is poured into the steel molds and compacted by vibrating machine. All specimens are removed from the molds after $24 \mathrm{~h}$ and cured in the conditions of $20 \pm 3^{\circ} \mathrm{C}$ and $95 \%$ relative humidity. The specimens cured for 28 days are used to test the static elasticity modulus under temperatures $-20^{\circ} \mathrm{C}, 0^{\circ} \mathrm{C}$, $20^{\circ} \mathrm{C}, 40^{\circ} \mathrm{C}$, and $60^{\circ} \mathrm{C}$ according to standard GB/T 500812002 [37]. In order to eliminate the influence of moisture, concrete specimens are wrapped by preservative film to maintain the stable moisture content. Three specimens are selected as one group for testing the elasticity modulus under specific temperature. The temperatures are jointly controlled by refrigerator and oven. The former is used for $-50^{\circ} \mathrm{C}-0^{\circ} \mathrm{C}$, while the latter is used for $20^{\circ} \mathrm{C}-300^{\circ} \mathrm{C}$. Each group of specimens are placed in temperature control apparatus for $4 \mathrm{~h}$ to make the temperature at the center of specimen be

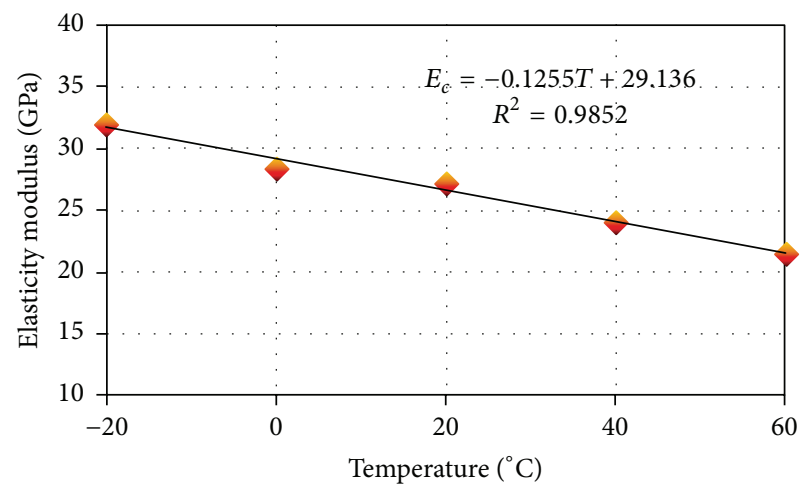

FIGURE 10: Temperature effect on the elasticity modulus of concrete.

consistent with setting temperature before testing [38]. The testing results of elasticity modulus under five temperature grades are illustrated in Figure 10. As can be seen, the elasticity modulus is improved by $48.3 \%$ as the temperature decreases from $60^{\circ} \mathrm{C}$ to $-20^{\circ} \mathrm{C}$. Linear fitting is performed to represent the relationship between elasticity modulus and temperature. It demonstrates a significant linear negative correlation between them. Although only the elasticity moduli under five temperature grades are tested in Jiao et al.s study, the magnitude of the change rate of elasticity modulus with respect to temperature is credible. Due to the weak statistical relationship between elasticity modulus and temperature, the detailed testing is a subject for further investigation.

Based on the fitted linear formula in Figure 10, thermal coefficient of elasticity modulus corresponding to the elasticity modulus at temperature $0^{\circ} \mathrm{C}$ is expressed as the ratio of slope to intercept:

$$
\theta_{E}=\frac{-0.1255}{29.136}=-4.31 \times 10^{-3} /{ }^{\circ} \mathrm{C} .
$$

From (6) and (7), a theoretical variation percentage of modal frequency for concrete slab and beam is $0.215 \%$ per degree Celsius corresponding to the modal frequency at temperature $0^{\circ} \mathrm{C}$. A finite element (FE) model of concrete slab is constructed using the ANSYS to demonstrate the derived theoretical variation percentage of modal frequency, as shown in Figure 11. It is modeled using the 3D solid elements (Solid 65). The values of material parameters used for the FE model are as follows: the elasticity modulus is temperature-dependent as described in Figure 10, material density is $\rho=2500 \mathrm{~kg} / \mathrm{m}^{3}$, and Poisson's ratio is $\mu=0.2$. These parameters are inputted into FE model to calculate modal frequencies with respect to temperatures. The Block Lanczos method in ANSYS is adopted to perform the modal analysis for the FE model of concrete slab [39, 40].

The obtained first four modal frequencies under different temperatures and corresponding linear fitting formulas are illustrated in Figure 12. It is shown that the variations of calculated modal frequencies match the tendency of elasticity modulus versus temperature. As the elasticity modulus used in FE model is referred to those in Jiao et al's study and is not exactly the same as the real ones in this paper, the calculated modal frequencies are different from the measurements. 


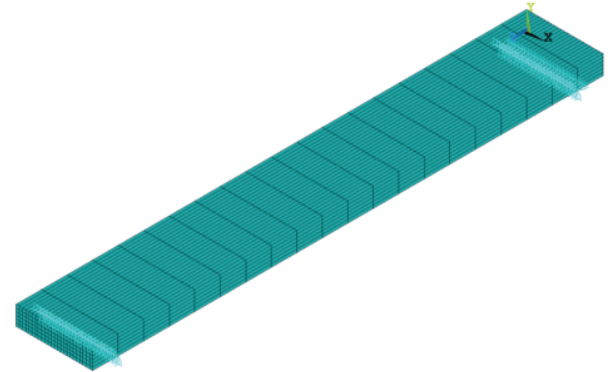

FIGURE 11: FE model of the concrete slab.

TABLE 4: The variation percentage of modal frequencies for $\mathrm{FE}$ model.

\begin{tabular}{lcccc}
\hline Mode & 1 & 2 & 3 & 4 \\
\hline Variation percentage (\%) & -0.22615 & -0.22632 & -0.22633 & -0.22632 \\
\hline
\end{tabular}

The FE model is not updated here to match the identified modal frequencies as this is not the objective of the present study. It is focused on the variation percentage of modal frequencies to verify the accuracy of theoretical analysis. The variation percentages of modal frequencies with respect to the modal frequencies at temperature $0^{\circ} \mathrm{C}$ are listed in Table 4 . It indicates that modal frequencies of FE model are decreased by $0.226 \%$ per degree Celsius, which shows a good agreement with theoretical results $(0.215 \%)$. The numerical calculation results of modal frequencies demonstrate the accuracy of theoretical analysis.

\subsection{Correlation between Modal Frequency and Temperature.} In vibration-based structural damage identification, temperature influence on modal frequencies is necessary to be eliminated through parametric approaches. A model of relationship between modal frequencies and temperature must be developed in the first step. In this paper, correlations between modal frequencies and temperatures (air temperature, surface temperature, and mean temperature) are analyzed. Air temperature is the temperature measured by digital temperature and humidity sensor in ambient environment. The surface temperature is decided as the mean value of temperatures measured by thermocouples ( $\mathrm{SH} 1, \mathrm{SH} 7$, SW1, and SW17) for the slab and (BH1, BH7, BW1, and BW7) for the beam. Mean temperature is obtained by averaging the temperatures from all the thermocouples in the cross section at mid-span. The correlations between the first four modal frequencies and temperatures are illustrated in Figures 13 and 14. The obvious negative correlations between modal frequencies and temperatures can be shown. And one can also observe that dispersion degrees of samples are different among three correlation models. To quantitatively analyze the correlations between modal frequencies and temperatures, coefficients of determination $\left(R^{2}\right)$, as the square of coefficient of correlation, are calculated and listed in Table 5 . It is found that $R^{2}$ between modal frequencies and mean temperatures
TABLE 5: $R^{2}$ between modal frequencies and temperatures.

\begin{tabular}{lccccc}
\hline \multirow{2}{*}{ Structure } & \multirow{2}{*}{ Temperature } & \multicolumn{4}{c}{ Mode } \\
& & 1 & 2 & 3 & 4 \\
\hline \multirow{3}{*}{ Slab } & Air temperature & 0.778 & 0.715 & 0.804 & 0.702 \\
& Surface temperature & 0.874 & 0.856 & 0.901 & 0.863 \\
& Mean temperature & 0.911 & 0.903 & 0.925 & 0.915 \\
\hline \multirow{3}{*}{ Beam } & Air temperature & 0.784 & 0.679 & 0.820 & 0.667 \\
& Surface temperature & 0.886 & 0.801 & 0.855 & 0.752 \\
& Mean temperature & 0.913 & 0.853 & 0.909 & 0.834 \\
\hline
\end{tabular}

TABLE 6: Regression coefficient and variation percentage of SLRM.

\begin{tabular}{lcccc}
\hline Structure & Mode & $b_{0}(\mathrm{~Hz})$ & $b_{\text {mean }}\left(\mathrm{Hz} /{ }^{\circ} \mathrm{C}\right)$ & $b_{\text {mean }} / b_{0}(\%)$ \\
\hline \multirow{4}{*}{ Slab } & 1 & 19.50 & -0.038 & -0.195 \\
& 2 & 85.41 & -0.184 & -0.215 \\
& 3 & 188.6 & -0.358 & -0.190 \\
& 4 & 325.8 & -0.528 & -0.162 \\
\hline \multirow{4}{*}{ Beam } & 1 & 52.63 & -0.091 & -0.173 \\
& 2 & 149.8 & -0.502 & -0.335 \\
& 3 & 515.3 & -1.197 & -0.232 \\
& 4 & 751.4 & -0.867 & -0.115 \\
\hline
\end{tabular}

are obviously larger than air temperature and surface temperature, which indicates the more significant correlations between modal frequencies and mean temperatures for slab and beam. Therefore, the relationship between modal frequencies and temperature cannot be sufficiently captured using air temperature or surface temperature. Comprehensive consideration of temperature distribution throughout the slab and beam will improve the correlation.

4.3. Simple Linear Regression Model. The higher correlation between modal frequencies and mean temperature demonstrates that the SLRM possesses favorable fitting performance. The SLRM between modal frequency and mean temperatures is established as

$$
f_{s}=b_{0}+b_{\text {mean }} T_{\text {mean }} \text {, }
$$

where $f_{s}$ is the modal frequency fitted by SLRM, $T_{\text {mean }}$ is mean temperature, and $b_{0}$ and $b_{\text {mean }}$ are the undetermined regression coefficients. For comparing the variation percentage of modal frequencies versus mean temperature, the slope $\left(b_{\text {mean }}\right)$ is normalized to the intercept $\left(b_{0}\right)$. The regression coefficients and variation percentages are listed in Table 6.

As can be seen from Table 6, modal frequencies are decreased by $0.12 \%-0.33 \%$ per degree Celsius corresponding to modal frequencies at temperature $0^{\circ} \mathrm{C}$, which agrees with the results $(0.215 \%)$ from theoretical analysis. It demonstrates that the variation percentage of modal frequency is a function of thermal coefficient of concrete elasticity modulus. As for the beam, the relative variation percentages of modal frequencies in modes 2 and 4 significantly diverge from the theoretical value. In addition, $R^{2}$ between modal frequencies in modes 2 and 4 and mean temperatures are smaller than 


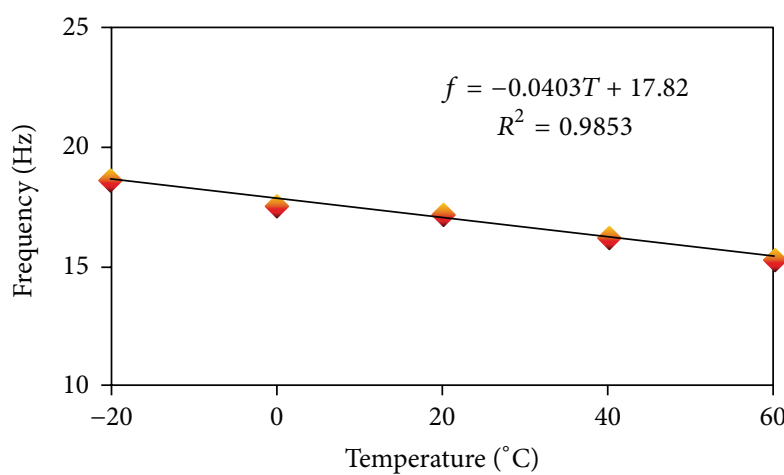

(a) First mode

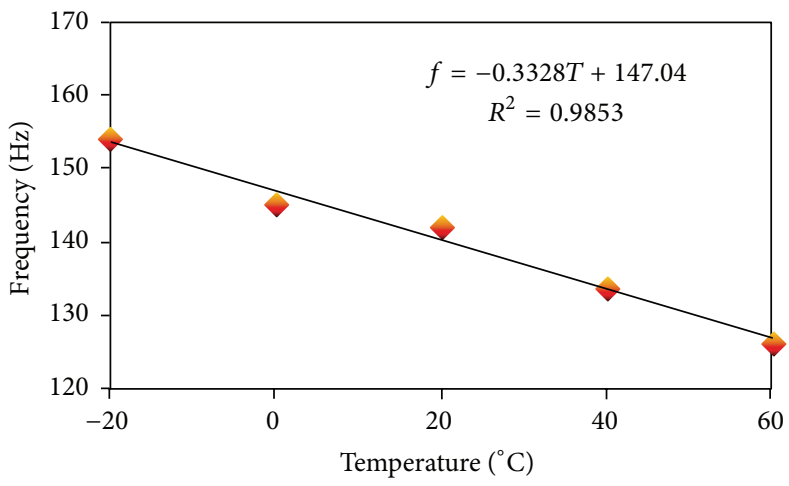

(c) Third mode

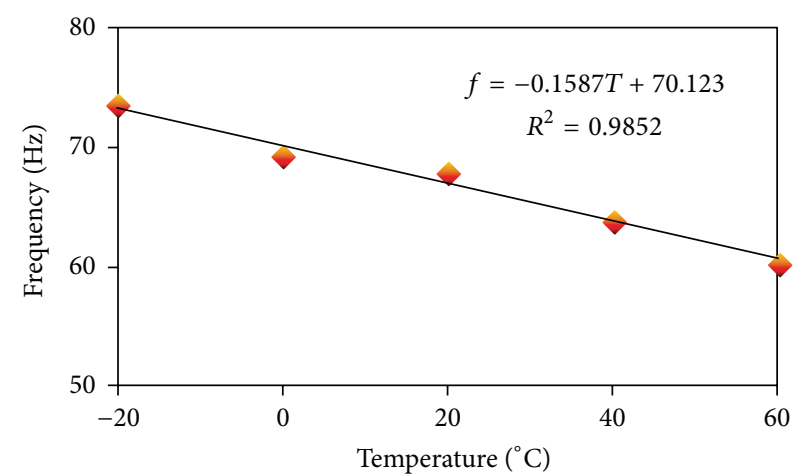

(b) Second mode

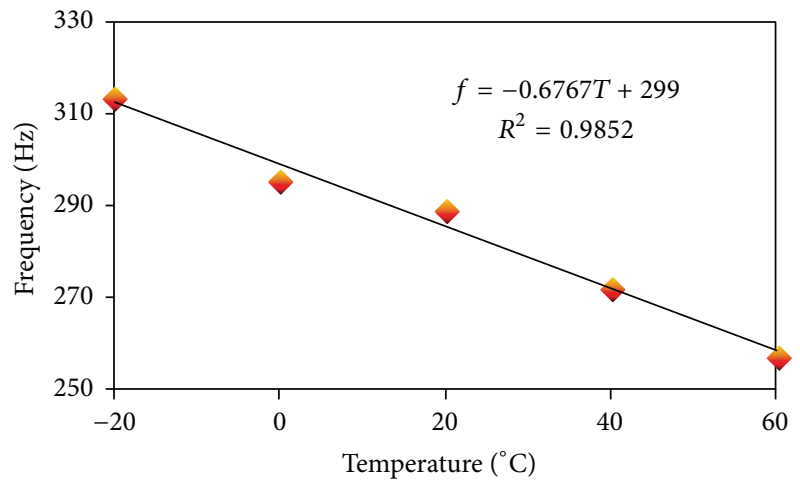

(d) Fourth mode

FIGURE 12: Modal frequencies of FE model under different temperature.

others. This indicates that the SLRM could not accurately quantify the temperature influence on modal frequencies due to the nonuniform and time-dependent properties of temperature distribution in the RC beam.

4.4. Multiple Linear Regression Model. Mean temperature is employed in the construction of SLRM. As the temperature distribution of bridge is significantly nonuniform and time-dependent, the unsatisfactory quantitative results are obtained by using mean temperature, especially for the beam. Therefore, the nonuniform temperature distribution in RC beam is important to be considered for accurately quantifying temperature effect on modal frequencies. MLRM is developed considering nonuniform temperature distribution and expressed as

$$
f_{m}=\beta_{0}+\beta_{1} T_{0}+\beta_{2} T_{1}+\beta_{3} T_{2}+\beta_{4} T_{3}+\beta_{5} T_{4},
$$

where $f_{m}$ is modal frequency predicted by MLRM, $\beta_{0}-\beta_{5}$ are regression coefficients, and $T_{0}-T_{4}$ are explanatory variables. Temperature at the center and corresponding temperature differences are used to describe the nonuniform temperature distribution. $T_{0}$ is the temperature measured from thermocouple BH4. $T_{1}, T_{2}, T_{3}$, and $T_{4}$ represent the temperature differences between $T_{0}$ and the temperatures at $\mathrm{BH} 1, \mathrm{BH}$, BW1, and BW7. Specific explanations are shown in Figure 15.
A total of 112 samples are obtained during the monitoring period. The samples measured on 1 November 2015 are chosen as testing samples to verify the prediction performances of quantitative models, and other 104 samples are used as training samples to construct quantitative models. The MLRM between modal frequencies and temperature variables $\left(T_{0}, T_{1}, T_{2}, T_{3}\right.$, and $\left.T_{4}\right)$ constructed by 104 training samples are listed as follows:

$$
\begin{aligned}
f_{1}= & 52.6471-0.0932 T_{0}-0.0311 T_{1}+0.0466 T_{2} \\
& +0.0088 T_{3}+0.0235 T_{4} \quad\left(R^{2}=0.958\right), \\
f_{2}= & 149.8887-0.5108 T_{0}+0.0608 T_{1}-0.2534 T_{2} \\
& +0.0575 T_{3}+7.613 e^{-4} T_{4} \quad\left(R^{2}=0.929\right), \\
f_{3}= & 515.0595-1.2248 T_{0}+0.2817 T_{1}-0.8516 T_{2} \\
& -0.0884 T_{3}+0.4007 T_{4} \quad\left(R^{2}=0.935\right), \\
f_{4}= & 752.1630-0.8867 T_{0}+0.1816 T_{1}-0.9993 T_{2} \\
& +0.3344 T_{3}-0.4321 T_{4} \quad\left(R^{2}=0.910\right) .
\end{aligned}
$$

The statistics of $R^{2}$ for 104 training samples are calculated as $0.958,0.929,0.935$, and 0.910 , which are much higher than SLRM. This indicates that MLRM can achieve a more 

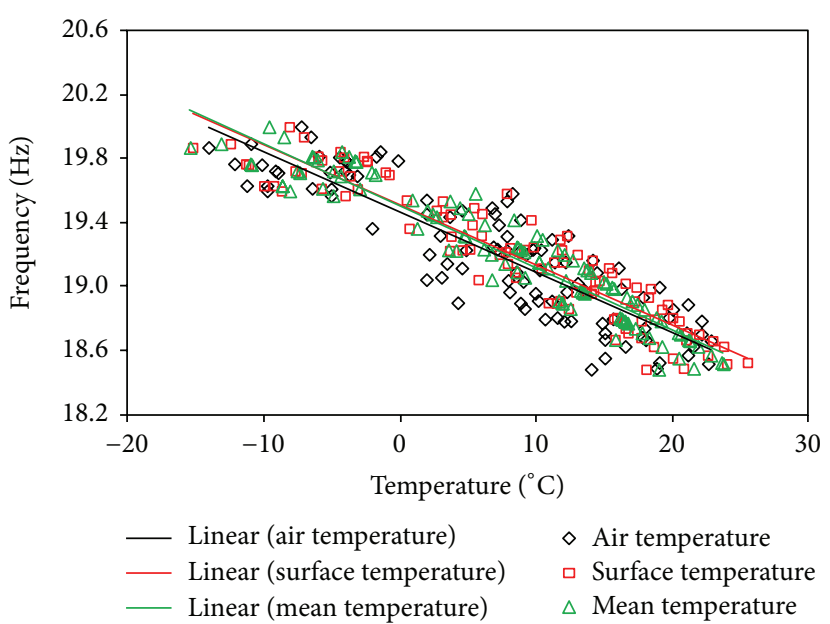

(a) First mode

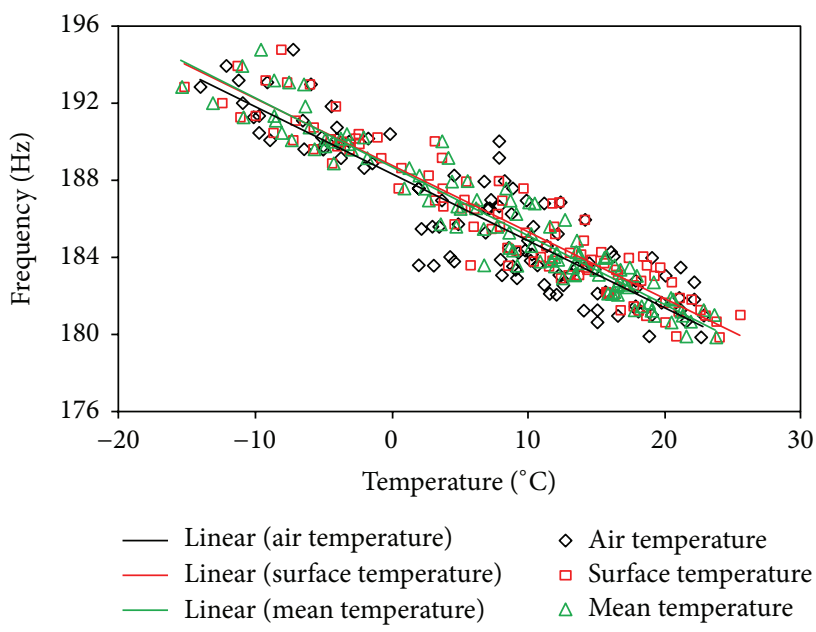

(c) Third mode

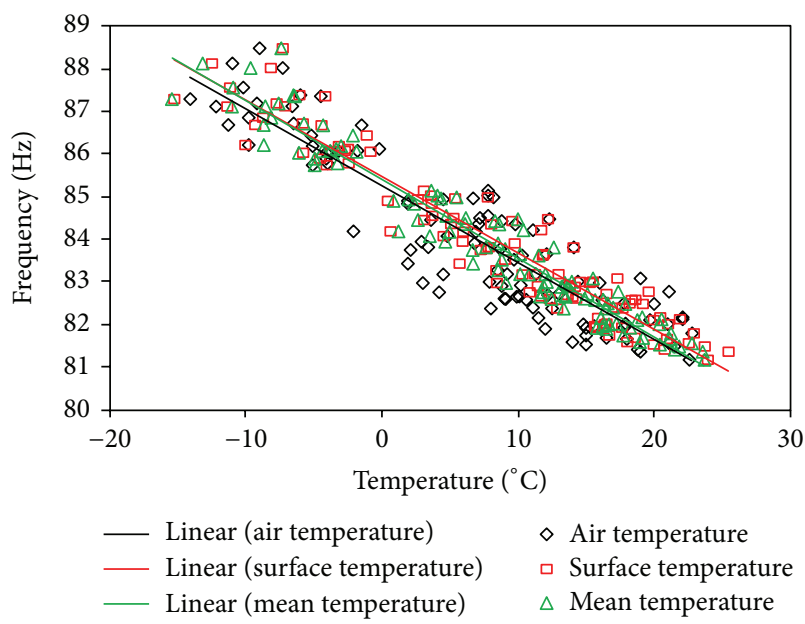

(b) Second mode

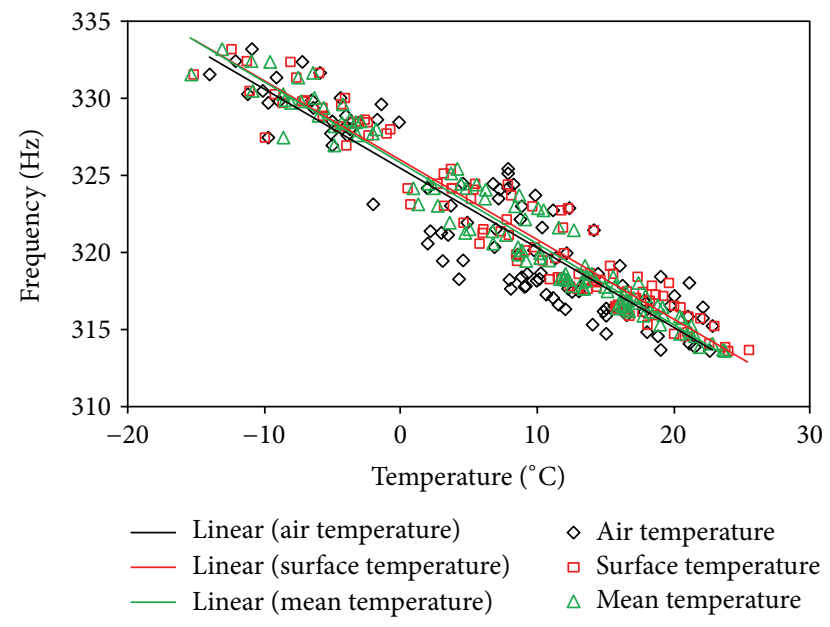

(d) Fourth mode

Figure 13: Correlations between modal frequencies and temperatures for the slab.

favorable quantification for temperature influence on modal frequencies.

4.5. Performance Validation. The quantitative models including SLRM and MLRM are constructed by use of the 104 training samples. SLRM adopts mean temperature as input variable, and the MLRM takes account of temperature variables $T_{0}, T_{1}, T_{2}, T_{3}$, and $T_{4}$ along both width and height directions. The reproduction capability of the quantitative models is examined using the training samples. By feeding temperature variables in training samples into the constructed quantitative models, the reproduced modal frequencies are obtained. Figure 16 shows the reproduced and identified modal frequencies for the 104 training samples. In trend, the modal frequencies reproduced by SLRM and MLRM vary in step with the identified modal frequencies, whereas some discrepancies exist in magnitude. It can be seen that modal frequencies reproduced by MLRM agree with the identified modal frequencies in both trend and magnitude, which verify the better reproduction capability of MLRM. In order to quantify and rank the reproduction capability of quantitative models, root mean squared error (RMSE) is adopted and expressed as follows:

$$
\mathrm{RMSE}=\sqrt{\frac{\sum_{i=1}^{n}\left(f_{i}-\widehat{f}_{i}\right)^{2}}{n}},
$$

where $n$ is the number of samples, $f$ and $\widehat{f}$ represent the identified and reproduced modal frequencies, respectively. RMSE values between identified and reproduced modal frequencies for the first four modes are illustrated in Table 7. It is observed that MLRM generates a lower RMSE, which reveals that MLRM has a higher accuracy in reproducing the training samples. In addition, it also demonstrates that the nonuniform temperature distribution should be taken into account in the construction of quantitative models.

Quantifying the temperature influence on modal frequencies is essential in vibration-based damage detection. 


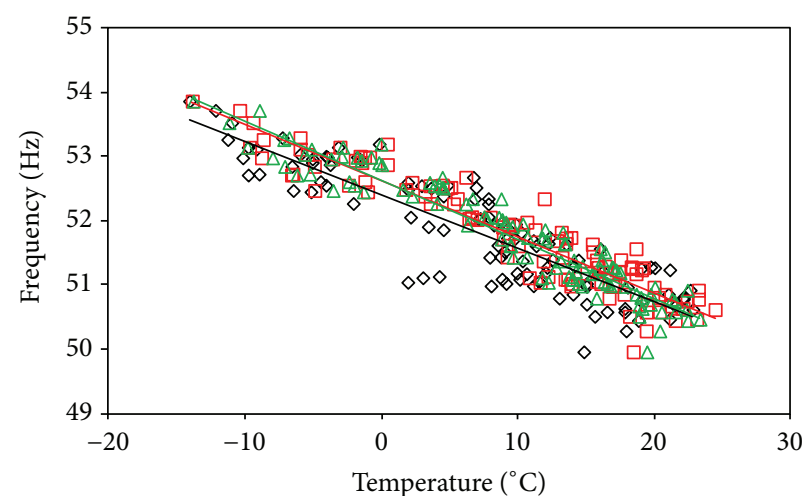

_ Linear (air temperature)
L Linear (surface temperature)
L Linear (mean temperature)

$\diamond$ Air temperature

- Surface temperature

$\triangle$ Mean temperature

(a) First mode

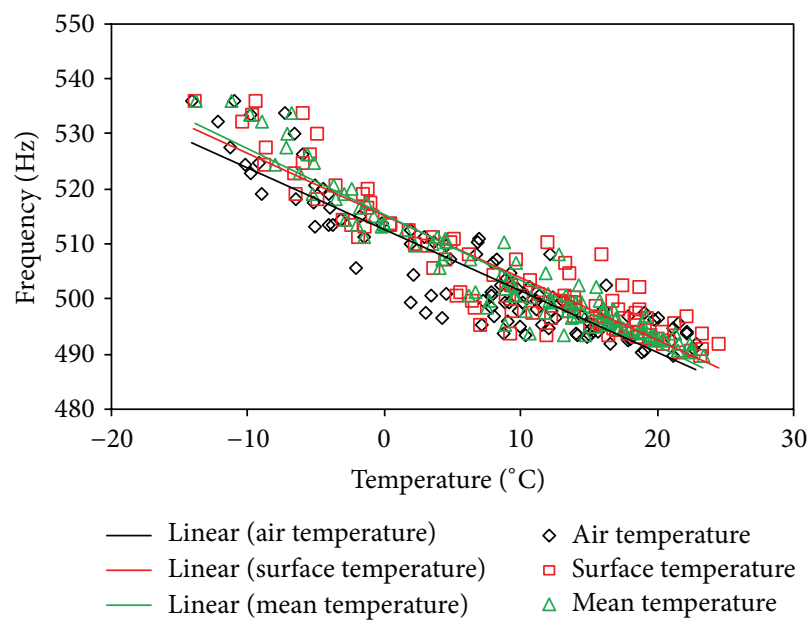

(c) Third mode

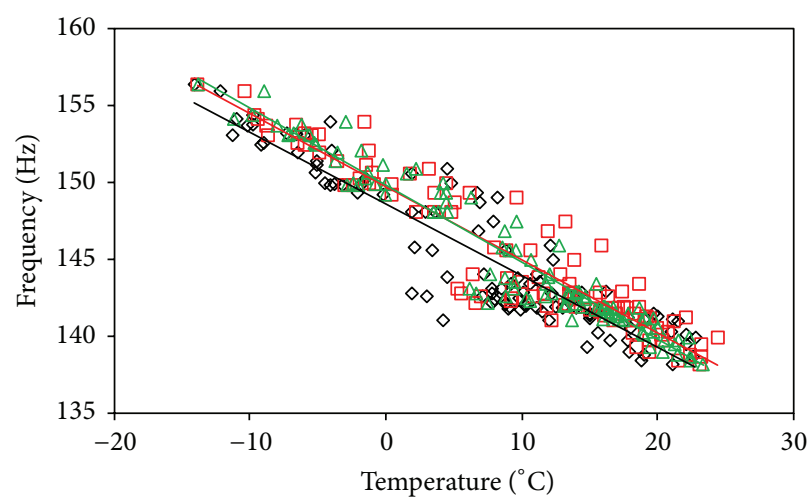

_- Linear (air temperature)
Linear (surface temperature)
L Linear (mean temperature)

$\diamond$ Air temperature

- Surface temperature

$\triangle$ Mean temperature

(b) Second mode

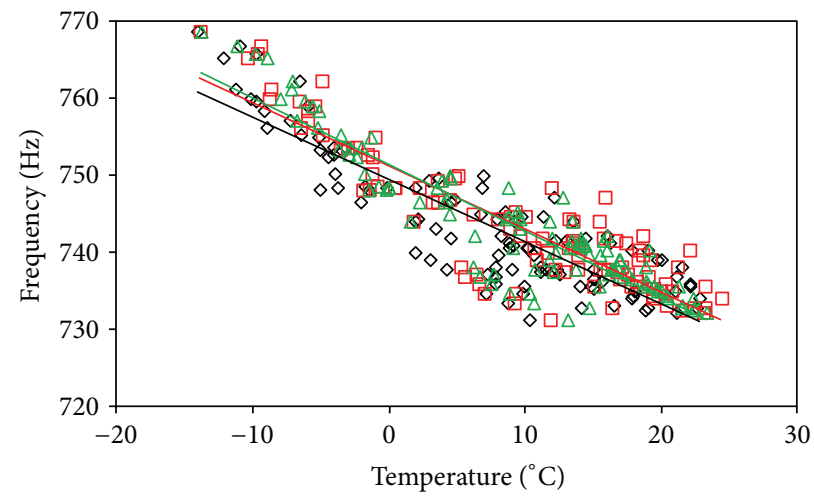

Linear (air temperature)
L Linear (surface temperature)
Linear (mean temperature)

$\diamond$ Air temperature

$\square$ Surface temperature

$\triangle$ Mean temperature

(d) Fourth mode

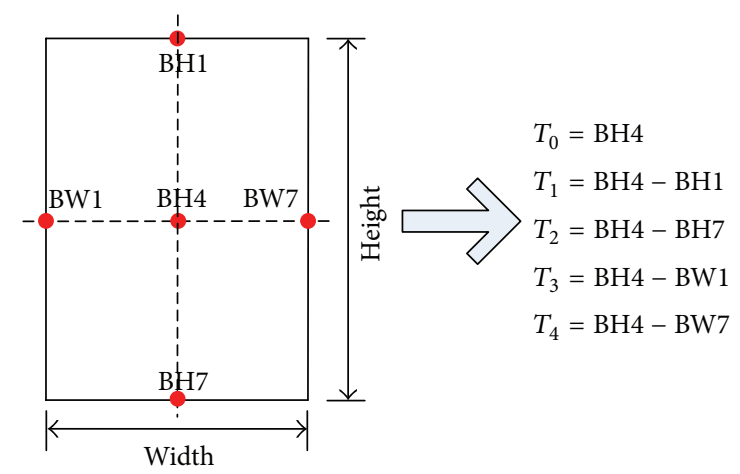

Figure 15: Temperature variables in multiple linear regression model.

Therefore, corresponding prediction capabilities of quantitative models are of the most concern. Testing samples measured on 1 November 2015 are used to verify the prediction
TABLE 7: RMSE of reproduced modal frequencies.

\begin{tabular}{lcccc}
\hline \multirow{2}{*}{ Model } & \multicolumn{5}{c}{ Mode } \\
& 1 & 2 & 3 & 4 \\
\hline SLRM & 0.6284 & 2.5759 & 7.0974 & 7.0601 \\
MLRM & 0.5051 & 2.1832 & 5.4944 & 5.1593 \\
\hline
\end{tabular}

capabilities of quantitative models. The temperature data in testing samples are presented into quantitative models for obtaining the predicted modal frequencies. Figure 17 illustrates the comparison between the predicted and identified modal frequencies. Similar to the reproduction phase, the predicted modal frequencies by SLRM and MLRM vary in step with the identified modal frequencies but deviate from the identified modal frequencies in magnitude. The statistics of RMSE are summarized in Table 8. MLRM achieve lower RMSE, which indicates that MLRM possess better prediction capability for testing samples. 


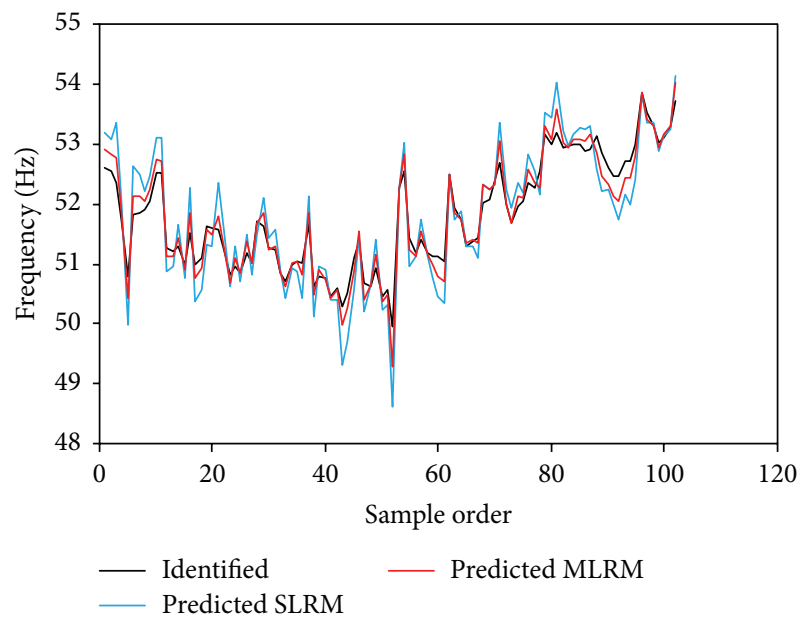

(a) First mode

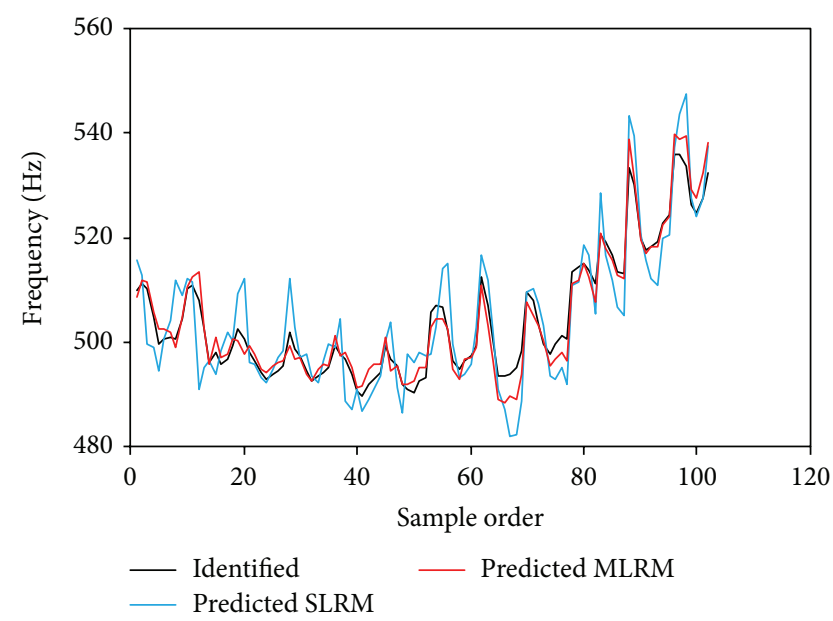

(c) Third mode

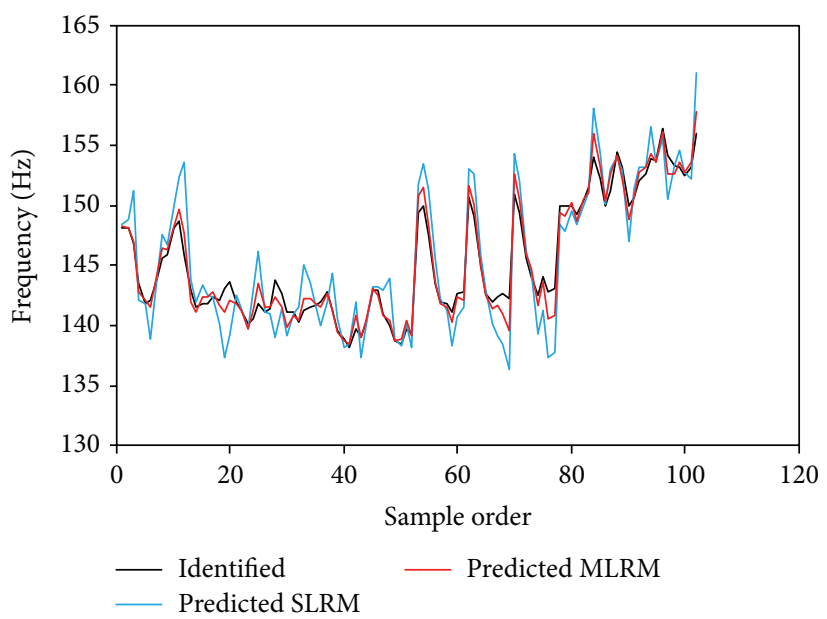

(b) Second mode

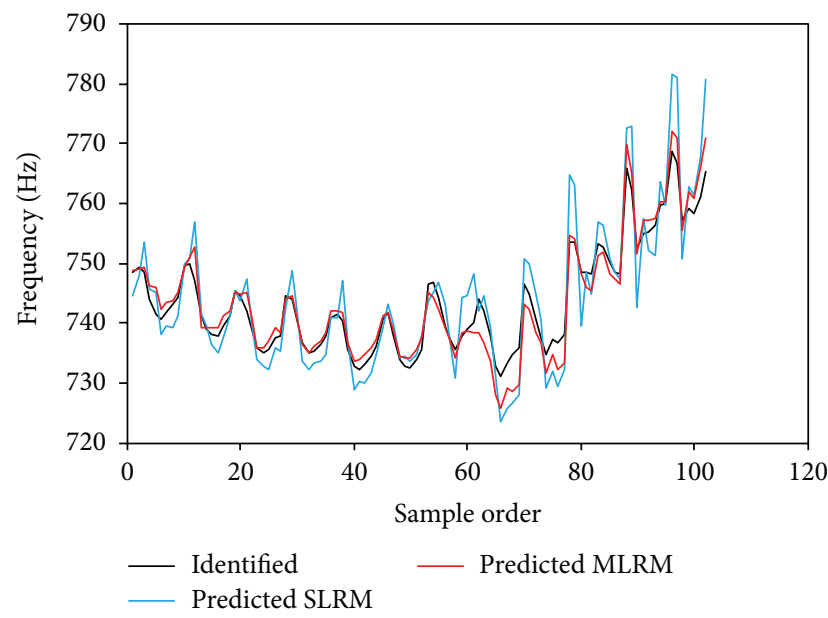

(d) Fourth mode

FIGURE 16: Comparison between the reproduced and identified modal frequencies for training samples.

TABLE 8: RMSE of predicted modal frequencies.

\begin{tabular}{lcccc}
\hline \multirow{2}{*}{ Model } & \multicolumn{4}{c}{ Mode } \\
& 1 & 2 & 3 & 4 \\
\hline SLRM & 0.6300 & 2.6074 & 7.1337 & 7.1117 \\
MLRM & 0.5120 & 2.2273 & 5.5846 & 5.2544 \\
\hline
\end{tabular}

According to the reproduction and prediction results of SLRM and MLRM, MLRM possesses a better generalization performance for reproducing and predicting the modal frequencies induced by temperature change. It also reveals that nonuniform temperature distribution throughout the bridge must be considered to obtain the accurate and reliable quantitative models for estimating temperature effect on modal frequencies.

\section{Conclusion}

In this paper, RC slab and beam were constructed and placed outside the laboratory to periodically measure the modal frequencies and temperatures. The correlations between modal frequencies and air temperature, surface temperature, and mean temperature are comparatively analyzed. A new approach is proposed to quantify the temperature effect on modal frequencies considering nonuniform temperature distribution in RC structure. Some conclusions can be obtained as follows:

(1) Temperature distributions are nonuniform not only along height direction but also along width direction, which is more obvious in the beam than in slab. The reasons mainly lie in the fact that the sizes of height and width for the beam are close to each other and thermal transmissions occur at two dimensions with similar levels.

(2) During monitoring period, the first four modal frequencies vary by $5 \%-12 \%$, while air temperature changes from $-14.1^{\circ} \mathrm{C}$ to $22.8^{\circ} \mathrm{C}$, which is sufficient to mask the change of modal frequencies caused by structural damage. Moreover, modal frequencies 


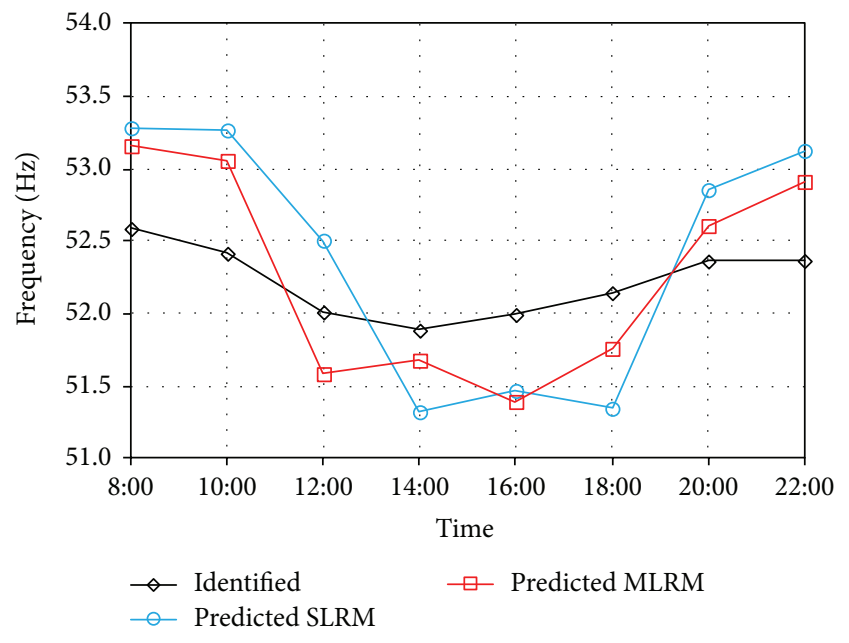

(a) First mode

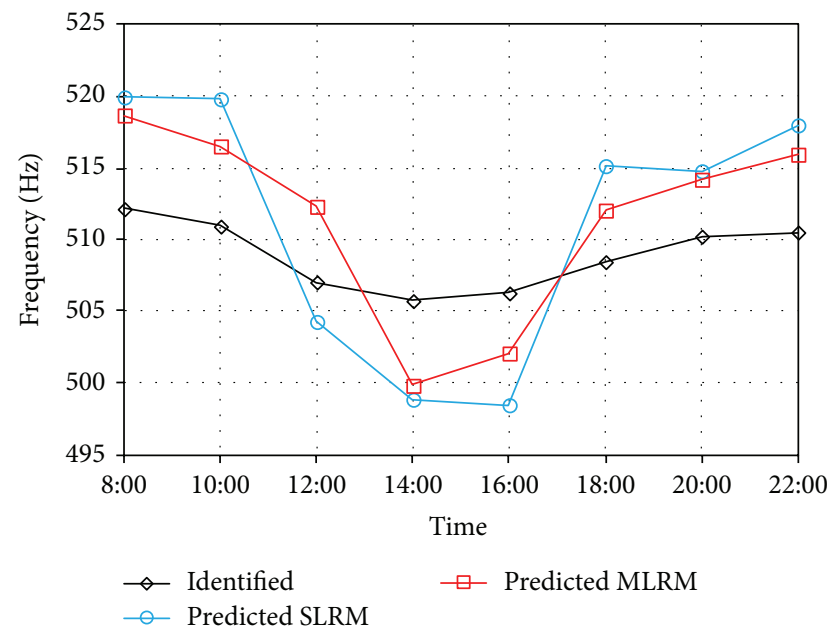

(c) Third mode

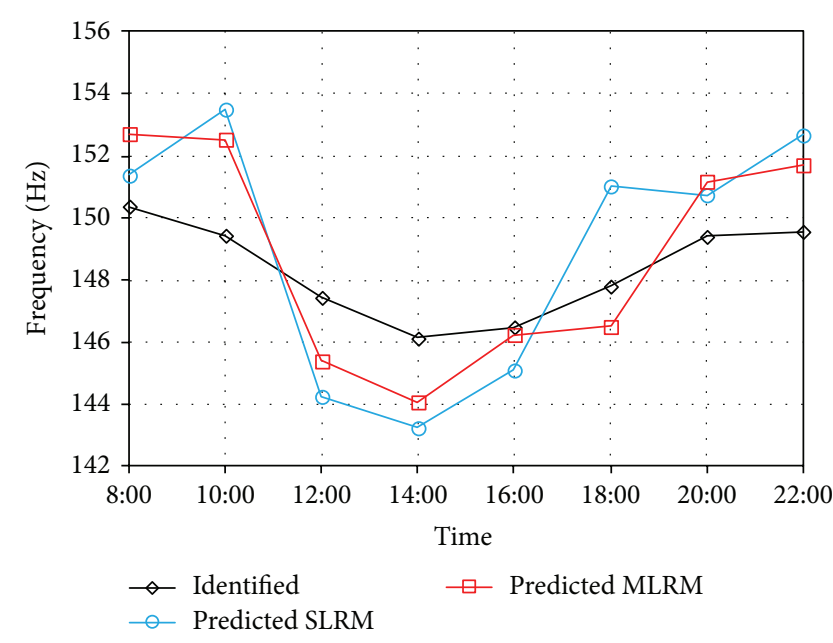

(b) Second mode

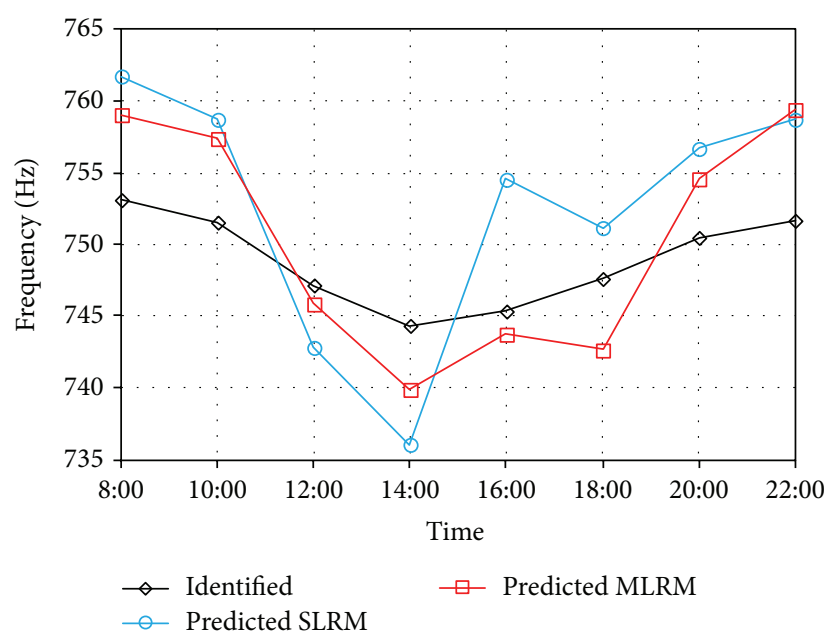

(d) Fourth mode

FIGURE 17: Comparison between the predicted and identified modal frequencies for testing samples.

decrease with the increasing of temperature, which exhibit a clear negative correlation.

(3) Coefficients of determination between modal frequencies and mean temperature are obviously larger than air temperature and surface temperature, which show a more significant correlation between modal frequencies and mean temperature. Therefore, nonuniform temperature distribution is necessary to be considered in correlation analysis between modal frequencies and temperature.

(4) For RC slab and beam, modal frequencies decrease by $0.12 \%-0.33 \%$ per degree Celsius corresponding to the modal frequencies at temperature $0^{\circ} \mathrm{C}$, which is consistent with the theoretical value $(0.215 \%)$. It indicates that the variation of concrete elasticity modulus with temperature is the main reason resulting in the changes of modal frequencies.

(5) MLRM is developed to formulate the relationship between modal frequencies and nonuniform temperature distribution. The reproduction and prediction performances are examined and compared with SLRM. RMSE between the identified and predicted modal frequencies indicates that the proposed MLRM achieves more favorable prediction accuracy. Meanwhile, comprehensive consideration of temperature variables along height and width directions is able to obtain better correlations.

\section{Competing Interests}

The authors declare that there are no competing interests regarding the publication of this paper.

\section{Acknowledgments}

The authors express their appreciation for the financial supports of National Natural Science Foundation of China (nos. 51378236 and 51408258), China Postdoctoral Science Foundation funded project (2014M560237 and 2015T80305), Fundamental Research Funds for the Central Universities 
(JCKY-QKJC06), and Science \& Technology Development Program of Jilin Province.

\section{References}

[1] Y. Q. Ni, X. W. Ye, and J. M. Ko, "Monitoring-based fatigue reliability assessment of steel bridges: analytical model and application," Journal of Structural Engineering, vol. 136, no. 12, pp. 1563-1573, 2010.

[2] J. M. Ko and Y. Q. Ni, “Technology developments in structural health monitoring of large-scale bridges," Engineering Structures, vol. 27, no. 12, pp. 1715-1725, 2005.

[3] Y. Q. Ni, X. W. Ye, and J. M. Ko, "Modeling of stress spectrum using long-term monitoring data and finite mixture distributions," Journal of Engineering Mechanics, vol. 138, no. 2, pp. 175183, 2011.

[4] P. J. S. Cruz and R. Salgado, "Performance of vibration-based damage detection methods in bridges," Computer-Aided Civil and Infrastructure Engineering, vol. 24, no. 1, pp. 62-79, 2009.

[5] A. Alvandi and C. Cremona, "Assessment of vibration-based damage identification techniques," Journal of Sound and Vibration, vol. 292, no. 1-2, pp. 179-202, 2006.

[6] I. Talebinejad, C. Fischer, and F. Ansari, "Numerical evaluation of vibration-based methods for damage assessment of cablestayed bridges," Computer-Aided Civil and Infrastructure Engineering, vol. 26, no. 3, pp. 239-251, 2011.

[7] J. H. G. Macdonald and W. E. Daniell, "Variation of modal parameters of a cable-stayed bridge identified from ambient vibration measurements and FE modelling," Engineering Structures, vol. 27, no. 13, pp. 1916-1930, 2005.

[8] D. F. Giraldo, S. J. Dyke, and J. M. Caicedo, "Damage detection accommodating varying environmental conditions," Structural Health Monitoring, vol. 5, no. 2, pp. 155-172, 2006.

[9] B. Moaveni and I. Behmanesh, "Effects of changing ambient temperature on finite element model updating of the Dowling Hall Footbridge," Engineering Structures, vol. 43, pp. 58-68, 2012.

[10] I. Behmanesh and B. Moaveni, "Probabilistic identification of simulated damage on the Dowling Hall footbridge through Bayesian finite element model updating," Structural Control and Health Monitoring, vol. 22, no. 3, pp. 463-483, 2015.

[11] H. Li, S. Li, J. Ou, and H. Li, "Modal identification of bridges under varying environmental conditions: temperature and wind effects," Structural Control and Health Monitoring, vol. 17, no. 5, pp. 495-512, 2010.

[12] G.-D. Zhou and T.-H. Yi, "A summary review of correlations between temperatures and vibration properties of long-span bridges," Mathematical Problems in Engineering, vol. 2014, Article ID 638209, 19 pages, 2014.

[13] Y. Xia, B. Chen, S. Weng, Y.-Q. Ni, and Y.-L. Xu, “Temperature effect on vibration properties of civil structures: a literature review and case studies," Journal of Civil Structural Health Monitoring, vol. 2, no. 1, pp. 29-46, 2012.

[14] É. Balmès, M. Basseville, F. Bourquin, L. Mevel, H. Nasser, and F. Treyssède, "Merging sensor data from multiple temperature scenarios for vibration monitoring of civil structures," Structural Health Monitoring, vol. 7, no. 2, pp. 129-142, 2008.

[15] Y. Xia, H. Hao, G. Zanardo, and A. Deeks, "Long term vibration monitoring of an RC slab: temperature and humidity effect," Engineering Structures, vol. 28, no. 3, pp. 441-452, 2006.
[16] P. Moser and B. Moaveni, "Environmental effects on the identified natural frequencies of the Dowling Hall Footbridge," Mechanical Systems and Signal Processing, vol. 25, no. 7, pp. 2336-2357, 2011.

[17] P. Cornwell, C. R. Farrar, S. W. Doebling, and H. Sohn, "Environmental variability of modal properties," Experimental Techniques, vol. 23, no. 6, pp. 45-48, 1999.

[18] H. Sohn, M. Dzwonczyk, E. G. Straser, A. S. Kiremidjian, K. Law, and T. Meng, "An experimental study of temperature effect on modal parameters of the Alamosa Canyon Bridge," Earthquake Engineering and Structural Dynamics, vol. 28, no. 7-8, pp. 879-897, 1999.

[19] C. R. Farrar, S. W. Doebling, P. J. Cornwell, and E. G. Straser, "Variability of modal parameters measured on the Alamosa Canyon bridge," in Proceedings of the 15th International Modal Analysis Conference (IMAC '97), pp. 257-263, Orlando, Fla, USA, February 1997.

[20] B. Peeters and G. De Roeck, "One-year monitoring of the Z24-bridge: environmental effectsversus damage events," Earthquake Engineering and Structural Dynamics, vol. 30, no. 2, pp. 149-171, 2001.

[21] J. Maeck, B. Peeters, and G. De Roeck, "Damage identification on the Z24-bridge using vibration monitoring analysis," in Proceedings of the European COST F3 Conference on System Identification and Structural Health Monitoring, pp. 233-242, 2000.

[22] V. Askegaard and P. Mossing, "Long term observation of RCbridge using changes in natural frequency," Nordic Concrete Research, vol. 7, pp. 20-27, 1988.

[23] S. L. Desjardins, N. A. Londoño, D. T. Lau, and H. Khoo, "Realtime data processing, analysis and visualization for structural monitoring of the confederation bridge," Advances in Structural Engineering, vol. 9, no. 1, pp. 141-157, 2006.

[24] C. Liu and J. T. DeWolf, "Effect of temperature on modal variability of a curved concrete bridge under ambient loads," Journal of Structural Engineering, vol. 133, no. 12, pp. 1742-1751, 2007.

[25] A. A. Mosavi, R. Seracino, and S. Rizkalla, "Effect of temperature on daily modal variability of a steel-concrete composite bridge," Journal of Bridge Engineering, vol. 17, no. 6, pp. 979-983, 2012.

[26] M. Breccolotti, G. Franceschini, and A. L. Materazzi, "Sensitivity of dynamic methods for damage detection in structural concrete bridges," Shock and Vibration, vol. 11, no. 3-4, pp. 383394, 2004.

[27] Y. L. Ding and A. Q. Li, “Temperature-induced variations of measured modal frequencies of steel box girder for a long-span suspension bridge," International Journal of Steel Structures, vol. 11, no. 2, pp. 145-155, 2011.

[28] C. Liu, J. T. DeWolf, and J.-H. Kim, "Development of a baseline for structural health monitoring for a curved post-tensioned concrete box-girder bridge," Engineering Structures, vol. 31, no. 12, pp. 3107-3115, 2009.

[29] J. D. Hios and S. D. Fassois, "Stochastic identification of temperature effects on the dynamics of a smart composite beam: assessment of multi-model and global model approaches," Smart Materials and Structures, vol. 18, no. 3, Article ID 035011, 2009.

[30] Y. Xia, Y.-L. Xu, Z.-L. Wei, H.-P. Zhu, and X.-Q. Zhou, "Variation of structural vibration characteristics versus nonuniform temperature distribution," Engineering Structures, vol. 33, no. 1, pp. 146-153, 2011. 
[31] National Standard of the People's Republic of China, "Standard for evaluation of concrete compressive strength," Tech. Rep. GB/T50107, 2010 (Chinese).

[32] P. Moser and B. Moaveni, "Design and deployment of a continuous monitoring system for the dowling hall footbridge," Experimental Techniques, vol. 37, no. 1, pp. 15-26, 2013.

[33] H. F. Zhou, Y. Q. Ni, and J. M. Ko, "Constructing input to neural networks for modeling temperature-caused modal variability: mean temperatures, effective temperatures, and principal components of temperatures," Engineering Structures, vol. 32, no. 6, pp. 1747-1759, 2010.

[34] X. He, Vibration-based damage identification and health monitoring of civil structures [Ph.D. thesis], Department of Structural Engineering, University of California, San Diego, San Diego, Calif, USA, 2008.

[35] R. Baldwin and M. A. North, "A stress-strain relationship for concrete at high temperatures," Magazine of Concrete Research, vol. 25, no. 85, pp. 208-212, 1973.

[36] Y. Jiao, H. Liu, X. Wang, Y. Zhang, G. Luo, and Y. Gong, "Temperature effect on mechanical properties and damage identification of concrete structure," Advances in Materials Science and Engineering, vol. 2014, Article ID 191360, 10 pages, 2014.

[37] National Standard of the People's Republic of China, "Standard for test method of mechanical properties on ordinary concrete," Tech. Rep. GB/T 50081-2002, 2003 (Chinese).

[38] B. Downie, Effect of moisture and temperature on the mechanical properties of concrete, [Ph.D. thesis], West Virginia University, Morgantown, Va, USA, 2005.

[39] G.-W. Chen, S. Beskhyroun, and P. Omenzetter, "Experimental investigation into amplitude-dependent modal properties of an eleven-span motorway bridge," Engineering Structures, vol. 107, pp. 80-100, 2016.

[40] R. G. Grimes, J. G. Lewis, and H. D. Simon, "A shifted block Lanczos algorithm for solving sparse symmetric generalized eigenproblems," SIAM Journal on Matrix Analysis and Applications, vol. 15, no. 1, pp. 228-272, 1994. 


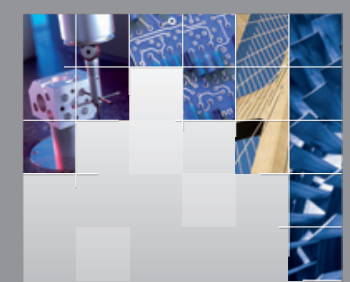

\section{Enfincering}
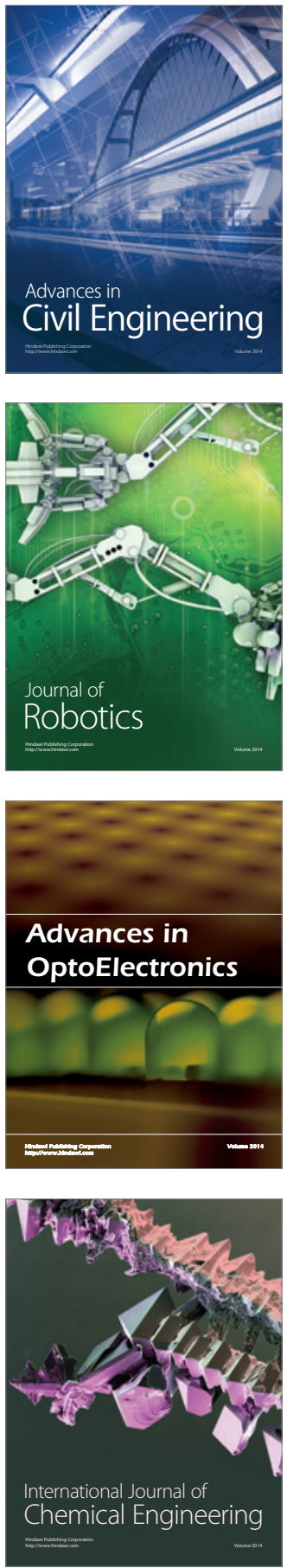

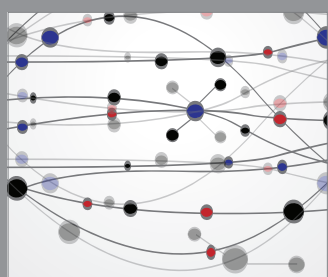

The Scientific World Journal

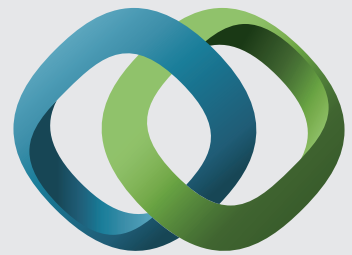

\section{Hindawi}

Submit your manuscripts at

http://www.hindawi.com
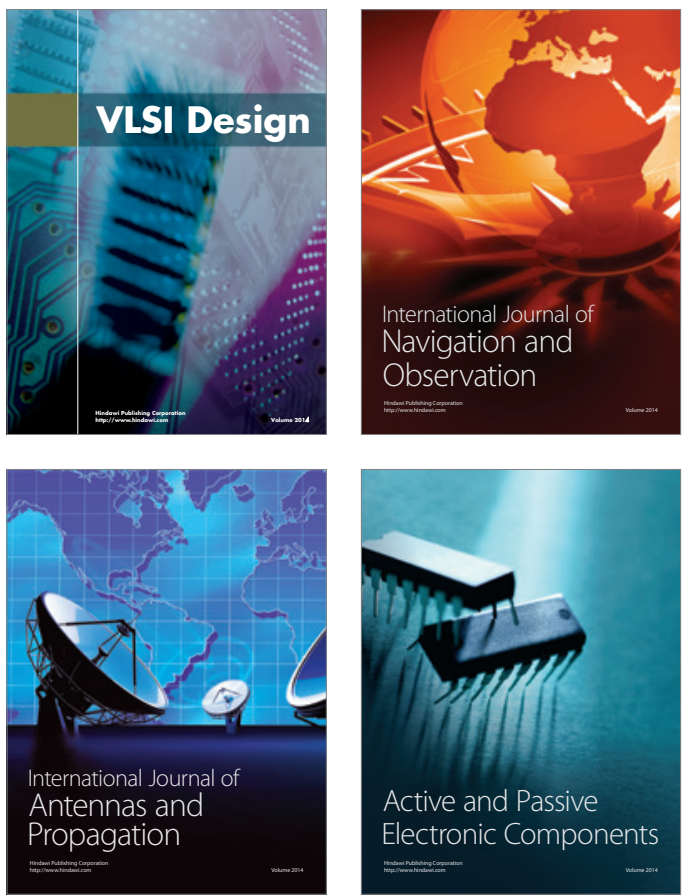
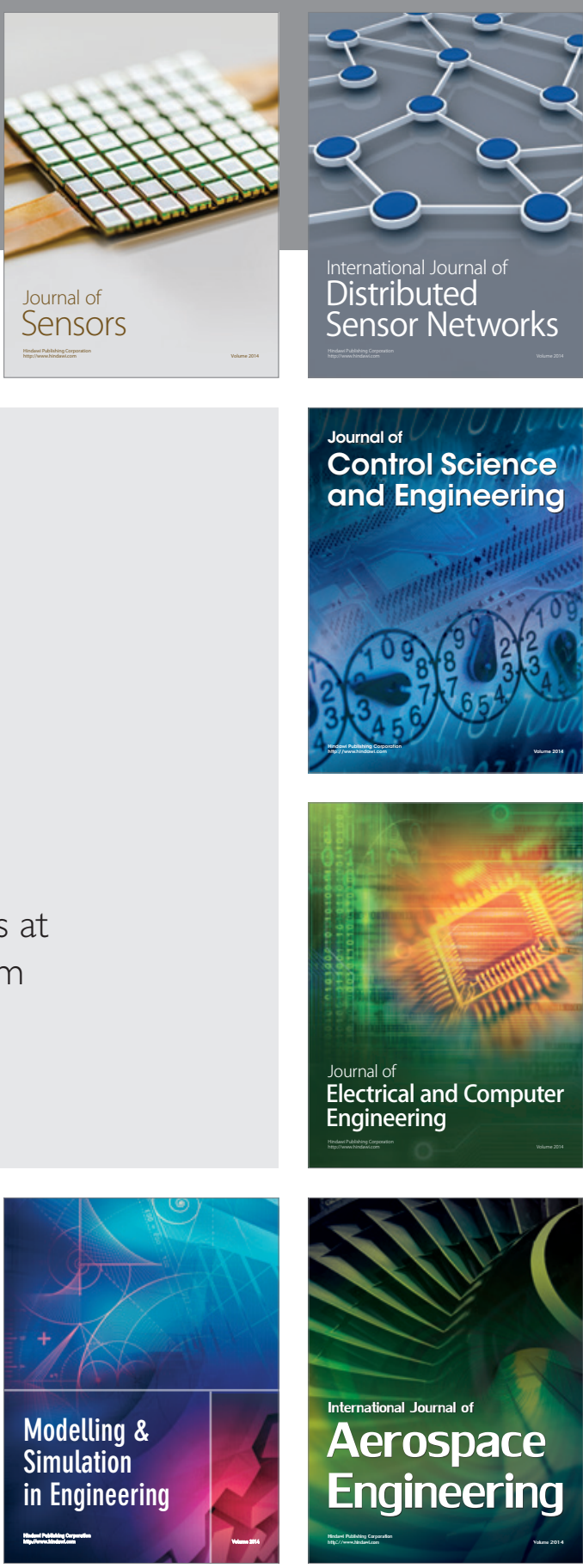

International Journal of

Distributed

Sensor Networks

Journal of

Control Science

and Engineering
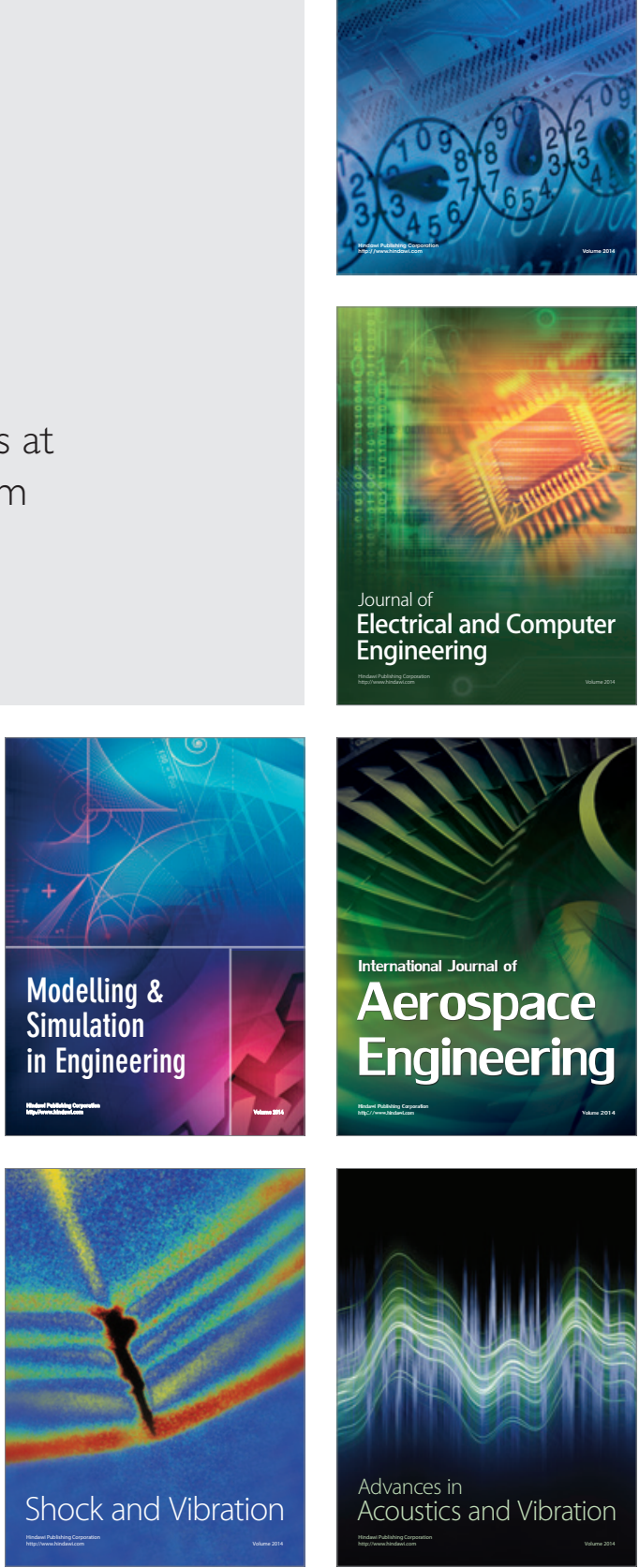